
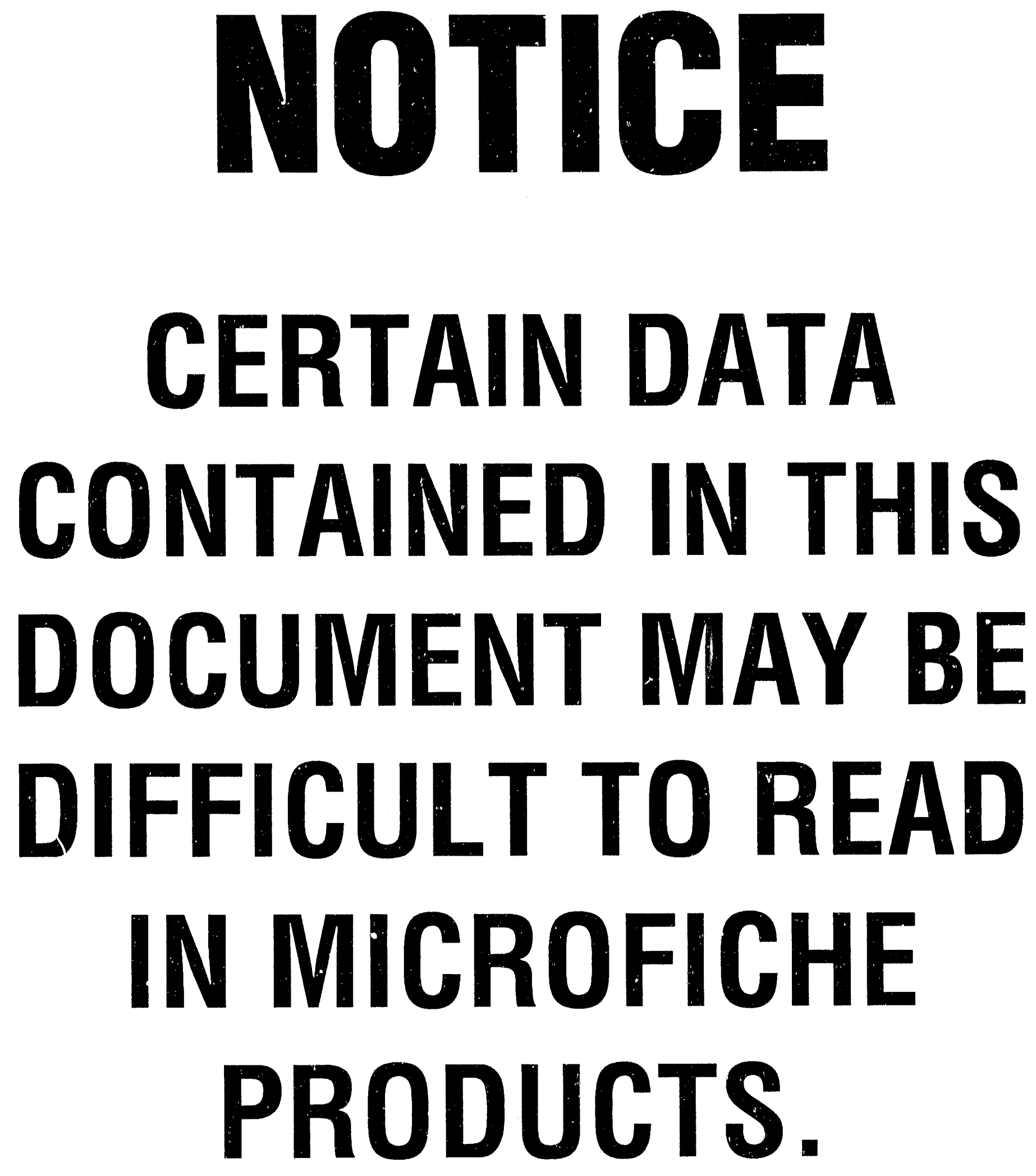


\title{
Spectroscopic Studies of Carbon containing Molecules and their break-up in PISCES-A
}

\author{
A.Pospieszczyk", Y.Ra, Y.Hirooka, R.W.Conn, \\ D.M.Goebel,B.LaBombard, R.E.Nygren
}

UCLA-PPG-1251

December, 1989

Department of Mechanical, Aerospace and Nuclear Engineering Institute of Plasma and Fusion Research

University of California, Los Angeles Los Angeles, CA 90024, USA

*"Work supported by U.S. DOE Contract No. DE-FG03-86ER52134

"Institut für Plasmaphysik, Association EURATOM-KFA

Forschungszentrum Jülich GmbH

Postfach 1913, D-5170 Jülich, FRG 


\section{DISCLAIMER}

This report was prepared as an account of nork sponsored by an agency of the United States Government. Neither the United States Government nor any agency thereof, nor any of their employees, makes any wartanty, express or implied, or assumes any legal liability or responsibility for the accuracy, completeness, or usefulness of any information, apparatus, product, or process disclosed, or represents that its use would not infringe privately owned rights. Reference herein to any specific commercial product, process, or service by trade name, tradernark, manufacturer, or otherwise, does not necessarily constitute or imply its endorsement, recommendation.,. or favoring by the United States Government or any agency thereof. The views and opinions of authors expressed herein do not necessarily state or reflect those of the United States Government or any agency thereof. 


\author{
Spectroscopic Studies of Carbon containing Molecules \\ and their break-up in PISCES-A \\ A.Pospieszczyk", Y.Ra, Y.Hirooka, R.W.Conn, D.M.Goebel, \\ B.LaBombard, R.E.Nygren \\ Department of Mechanical, Aerospace and Nuclear Engineering \\ Institute of Plasma and Fusion Research \\ University of California, Lus Angeles \\ Los Angeles, CA 90024, USA \\ "* Work supported by U.S. DOE Contract No. DE-FG03-86ER52134 \\ "Institut für Plasmaphysik, Association EURATOM-KFA \\ Forschungszentrum Jülich $\mathrm{GmbH}$ \\ Postfach 1913, D-5170 Jülich, FRG
}

\begin{abstract}
We have used the PISCES-A facility in order to study the behavior of carbon containing molecules in a representative plasma with parameters close to that of a tokamak boundary layer. $\mathrm{CH}_{4}$, $\mathrm{C}_{2} \mathrm{H}_{2}, \mathrm{C}_{2} \mathrm{H}_{4}, \mathrm{CO}$, and $\mathrm{CO}_{2}$ molecules were introduced through a slit aperture into a helium plasma and the radiation from these due to electronic excitation was spectrographically recorded. The imaging of the plasma onto the entrance slit of an $1.33 \mathrm{~m}$ McPherson optical spectrometer was chosen in such a way that simultaneous information about spectral and spatial distribution of the emission could be obtained by an attached photographic camera and an optical multichannel analyser (OMA). The recorded spectra show that many features in previously obtained spectra from limiters originate - beside from hydrocarbons - from carbonoxides, which seem to play a mayor role in the transport of carbon and oxygen. It was also possible to calibrate the radiation intensity of several molecular bands versus the known molecular influx so that an absolute determination of these fluxes from the wall of a fusion device could be done. Measurements of the attenuation of the individual species were carried out, which describe the penetration of carbon, oxygen, and hydrogen atoms into a discharge by taking into account individual steps in the molecular breakup process.
\end{abstract}




\section{INTRODUCTION}

In present day tokamaks carbon is one of the most widely used materials for limiters and wall coatings. However, carbon shows strong chemical reactions with oxygen and hydrogen, which can lead to an enhanced erosion by chemical sputtering. Therefore, it is important to know to which extent carbon containing molecules like $\mathrm{CH}_{4}$ or $\mathrm{CO}$ play a role in fueling and impurity release during plasma discharges. In the past there were several attempts to demonstrate the importance of molecuiar influxes into the plasma boundary layer especially for relatively low temperatures (around $T_{e}=20 \mathrm{eV}$ ); e.g. in TEXTOR [1],[2], JET [3], ASDEX [4],[5], DITE [6], and TFTR [7]. But these investigations mostly lacked a direct measurement of the molecular influx at the location, where it actually originates.

In order to overcome this problem emission spectroscopy is used in this work.

By this technique one can determine the strength and nature of the molecular sources even at locations, which are not easily accessible, and it can also be used to study the molecular breakup processes. From TFXTOR and JET, there are already spectrographic data on the molecules in the region of plasma facing components due to plasma surface interactions [1], [8]. However the identification of the bands is not so easy as one might think, as the existing spectra so far, which could be used for cumparison (see e.g. [9]), have been mostly exclusively obtained under non-plasma-boundary-like conditions. Therefore a unique identification of the observed bands is difficult; e.g. for the investigation of the $\mathrm{CH}$-band structure an alcohol flame was used (which inevitably also displays interfering $\mathrm{OH}$-bands). In addition there exists presently not many information concerning observable lines or bands with reasonable intensities, needed for absolute measurements for the interesting molecules in a plasma of tokamak boundary like conditions.

Therefore an attempt has been made to use a representative plasma with parameters close to that of a tokamak boundary layer in order to obtain a more reliable spectra and data base for present and future fusion devices in regard to carbon containing molecules and their radicals. A specific interest of this work is to study the following important breakup processes (for the ions indicated as well as for the neutrals):
a) $\mathrm{CH}_{4}{ }^{(+)} \rightarrow \mathrm{CH}_{3}^{(+)} \rightarrow \mathrm{CH}_{2}^{(+)} \rightarrow \mathrm{CH}^{(+)} \rightarrow \mathrm{CH}^{+}, \mathrm{C}^{(+)}, \mathrm{H}^{(+)}$
b) $\mathrm{CO} \rightarrow \mathrm{CO}^{+} \rightarrow \mathrm{C}^{(+)}, \mathrm{O}^{(+)}$

The significance of chain a) for an all-carbon-machine has already been demonstrated by [10] and [11] and the rates for the respective processes have been collated by [12]; the latter are not yet experimentally verified. As the molecular break-up chains are relatively long, small errors in the first steps can lead to strong deviations in the calculated $\mathrm{CH}_{-}, \mathrm{C}-$, and $\mathrm{H}$-distributions. Therefore it is important to measure the respective distributions as far as possible and compare these with calculations from Monte Carlo Codes. 
The cross sections and/or the respective rate coefficients for chain b) have been published by e.g. [13] and [14], and it is still important to verify these experimentally, as the role of CO in a tokamak plasma in a carbon surrounding seems to be a significant one [15].

\section{EXPERIMENTAL PROCEDURE}

A schematic diagram of the whole experimental apparatus is shown in figure 1. For simplicity the orthogonal planes of observation and main gas stream out of the nozzle are projected into one plane. In the following the experimental systems will be described in detail.

\section{A. The PISCES-A facility}

We have used the Plasma Interactive Surface Component Experimental Station A (PISCES-A) for the production of plasmas with parameters close to those of the tokamak boundary layer. The plasma is produced by a radiatively heated lanthanum hexaboride cathode supplying primary electrons to a reflex arc discharge. A uniform axial magnetic field of 0.02 to 0.14 Tesla confines the plasma to a cylindrical shape with a diameter of 6 to $10 \mathrm{~cm}$. Steady state plasmas with densities in the range of $10^{11}$ to $10^{13} \mathrm{~cm}^{-3}$ and electron temperatures up to $30 \mathrm{eV}$ are readily generated. These values correspond to typical conditions in the edge plasma of tokamaks. In standard operation, the sample, which is at the "floating potential", is immersed in the plasma column for testing through a modified end plate. More Details of PISCES-A operation can be found in the references [16],[17],[18].

For the measurenaent of the basic discharge parameters two probe systems were available in the observed plasma region of interest:

a) a stationary water-cooled Langmuir probe, the characteristics of which could be swept through from the ion- to the electron saturation current, and which allowed the determination of $T_{e}$ and $n_{e}$ for one spatial point on the axis. From the measured characteristics the electron distribution function, which plays a major role in the excitation process by electron collisions, could be derived.

b) a fast scanning ( $\leq 400 \mathrm{msec}$ ), pneumatically driven combination emissive/mach probe diagnostic, which allows to take a vertical profile within one "shot". Profiles of $n_{e}$ and $T_{e}$ can be routinely obtained by measuring the floating and the plasma potentials. A differentially pumped sliding seal allows the probe to be positioned for a fast vertical scan at various axial distances. By vertically scanning the plasma column through its centerline at uniformly spaced axial locations, a complete map of plasma parameters in the near presheath can be assembled. More details for this diagnostic technique can be found in [19]. 


\section{B. Gas injection system}

The gas injection system consisted of an absolutely calibrated pressure gauge, a capillary tube $(d=0.2 \mathrm{~cm}$ ) and a slit aperture (see fig. 1 and 2 ). The slit aperture had a size of $4 \mathrm{~mm}$ in the direction of the spectroscopic observation and $9.5 \mathrm{~mm}$ in the direction normal to it. This geometry had been chosen in order to simulate a larger, particle releasing object (e.g. a tokamak limiter) and to support the assumption of a plane geometry in the vertical direction as close as possible.

In order to keep the influx of particles as constant as possible during the experimental duration (occasionally up to 10 minutes) the gas flow was controlled by a needle valve and the total upstream pressure in the differentially pumped upstream volume was measured by a baratron (MKS 227AA$00001 \mathrm{~A})$. The flow rate $\mathrm{Q}$ into the PISCES-chamber was then given by

$$
Q=p_{\text {upatream }} \times C
$$

where $C$ is the conductance of a long capillary tube and given by

$$
C=3.27 \times 10^{-2} \frac{\mathrm{d}^{4}}{\eta \ell}-\overline{\mathrm{p}}
$$

where

$\overline{\mathrm{p}}$ : averaged pressure $0.5 \mathrm{p}_{\text {upatream }}$ (in PISCES) [Torr]

$\eta$ : viscosity of the gas used $[\mathrm{g} /(\mathrm{cm} \mathrm{sec}) \equiv$ poise $]$

$\mathrm{d}$ : diameter of the tube $[\mathrm{cm}]=0.2 \mathrm{~cm}$ (in PISCES)

$\ell:$ length of the tube $[\mathrm{cm}]=140 \mathrm{~cm}$ (in PISCES)

Taking these PISCES parameters into account, the resultant flow rate from equ. (1) will be:

$$
\mathrm{Q}=1.87 \times 10^{-7} \frac{\mathrm{p}_{\text {upstream }}^{2}}{\eta} \quad[\text { torr } \times 1 / \mathrm{sec}]
$$

or

$$
\mathrm{Q}=5.88 \times 10^{12} \frac{\mathrm{p}_{\text {upstream }}^{2}}{\eta} \quad[\text { molecules } / \mathrm{sec}]
$$

The $\eta$ is assumed to be pressure independent and is given by

$$
\eta=2.71 \times 10^{-21} \frac{\left(\mathrm{M}_{\mathrm{A}} \mathrm{T}\right)^{1 / 2}}{\sigma^{2}} \quad \text { [poise] }
$$


where

$\mathrm{M}_{\mathbf{A}}$ : atomic mass unit, $\mathrm{T}$ : gas temperature in $[\mathrm{K}], \sigma$, the diameter of the molecule in [cm] For the gases injected the following values for $\sigma$ (in units of $10^{-8} \mathrm{~cm}$ ) were used:

$\mathrm{CH}_{4}: 3.24, \mathrm{C}_{2} \mathrm{H}_{2}: 4.16, \mathrm{C}_{2} \mathrm{H}_{4}: 4.16, \mathrm{CO}: 3.15, \mathrm{CO}_{2}: 3.24$

\section{Spectroscopic diagnostics}

The optical diagnostic system for the observation of the light emission from the injected molecules consisted of a McPherson $1.33 \mathrm{~m}$ monochromator, which was equipped with a grating of 1200 groves $/ \mathrm{mm}$ resulting in a linear dispersion of 6 Angstrom $/ \mathrm{mm}$. The plasma was focussed by a single lens (focal length $=50 \mathrm{~cm}, \varnothing=5 \mathrm{~cm}$, magnification $=9$ ) onto the entrance slit in such a way that simultaneous information about spectral and spatial distribution of the emission could be obtained (see fig.2). In order to achieve this a $\mathrm{CaF}_{2}$-prism had been mounted in front of the entrance slit, which - by a rotation of $45^{\circ}$ - turned the vertical entrance slit into a horizontal position in the observation volume. In combination with the magnification by the lens, a slice of $0.6 \mathrm{~mm}$ in vertical and $9 \mathrm{~cm}$ in horizontal direction (from a $70 \mu \mathrm{m} \times 10 \mathrm{~mm}$ slit) of the plasma volume could be observed.

For spectrographic recordings of the emission a camera was attached in the focal plane of the exit slit. As recording material a high speed polaroid fiim was used with a sensitivity of ISO $3000 / 36^{\circ}$. It has a spectral sensitivity $\mathrm{r}$ rom $\approx 7000 \AA$ down to $\approx 3000 \AA$. The upper wavelength limit is the well known boundary to the infralled, the lower limit, however, is probably partly determined by the instant coating, which preserves the film against scratching. Polaroid films with even higher sensitivity (type 612: ISO $20000 / 44^{\circ}$ ) but no instant coatings display a much lower limit $(\approx 2000 \AA)$ [1]. This fact unfortunately prevented spectral measurements in the near UV, where mary of the investigated molecules emit intensive bands, although the optical components were capable of transmitting nearUV radiation. The size of a print was $8.5 \times 10.8 \mathrm{~cm}$, which allowed to record a spectral range of $\approx 500 \AA$ in one take. The two-dimensional recording over such a wide wavelength range can serve as a superb mean in order to obtain a qualitative overview over spatial and spectral distribution of the optical emission from a radiating species.

However, for quantitative results, one part of the information had to be omitted. Two types of detectors were attached to the spectrometer and could be alternatively used by turning a mirror in front of the exit slit. In order to obtain the total integrated photon emission along the line of sight, as experimentally described above, a photomultiplier with an S 20 cathode response was used as a detector. This sensitivity allowed to detect photon emission from the UV up to the near infrared. Thus light at $\lambda=8446 \AA$ from oxy'gen atoms could just be detected photoelectrically. For the detection of carbon atoms, which emit at $\lambda=9095 \AA$ only the optical multichannel analyzer (OMA) could be 
used. Both systems had been absolutely calibrated by a tungsten ribbon lamp, which was placed at the emission volume for that purpose.

The integrated photon emission along the penetration path into the plasma is a measure for the amount of flux of released particles per unit length of the source (in our case in the vertical direction), provided that the atoms (or molecules) are completely attenuated by electron collisions within the line of sight [1], [20]. The total number of particles is then obtained by multiplication with the whole length of emitting components. A formula to convert the measured brightness $B_{\text {tot }}$ into particle fluxes can be found e.g. in [21]. For completeness the derivation will be repeated here and the simplifications, which are valid for PISCES conditions, will be especially noted.

The flux of atoms into a plasma, which is assumed to be equivalent to the numbers of ionization events, is given by:

$$
\frac{d \phi_{A}(r)}{d r}=n_{A}(r) n_{e}(r)<\sigma_{I} v_{e}>
$$

or as integral version:

$$
\phi_{\Lambda}=\int_{r_{1}}^{r_{2}} n_{\Lambda}(r) n_{e}(r)<\sigma_{1} v_{e}>d r
$$

On the other hand, the emitted photon intensity following electron excitation is given by:

$$
B_{\text {tot }}=\frac{\Gamma}{4 \pi} \int_{r_{1}}^{r_{2}} n_{A}(r) n_{e}(r)<\sigma_{E m} v_{e}>d r
$$

where

$n_{A}(r) \quad$ : impurity density profile

$n_{e}(r) \quad$ : electron density profile

$\left\langle\sigma_{\mathrm{I}} \mathrm{v}_{\mathrm{e}}\right\rangle$ : ionization rate coefficient (a function of $\mathrm{T}_{\mathbf{e}}$ )

$\left\langle\sigma_{E_{m}} v_{e}\right\rangle$ : excitation rate coefficient for level $m$ (a function of $T_{e}$ )

$\Gamma \quad$ : branching ratio

By taking the ratio of equation (5a) and (6), one obtains a relation for the flux $\phi_{\mathbf{A}}$ as function of the measured total intensity: 


$$
\phi_{A}=\frac{4 \pi}{\Gamma} B_{t o t} \frac{\int_{1}^{r_{2}} n_{A}(r) n_{e}(r)<\sigma_{I} v_{e}>(r) d r}{\int_{1}^{r_{2}} n_{A}(r) n_{e}(r)<\sigma_{E m} v_{e}>(r) d r}
$$

where one has to substitute

$n_{A}(r)=n_{A}(0) \int_{v=0}^{\infty} f\left(v_{A}\right) \exp \left[-\frac{1}{v_{A_{1}}} \int_{r_{1}}^{r_{2}} n_{e}(r)<\sigma_{I} v_{e}>d r\right] d v_{A}$

with

$d n_{A}(r)=-n_{A}(r) n_{e}<\sigma_{I} v_{e}>\frac{d r}{v_{A}}$

$\operatorname{df}\left(v_{A}\right)=\frac{4}{\pi v_{0}} \times d v_{A}\left[1+\left[\frac{v_{A}}{v_{0}}\right]^{2}\right]^{-2}$

A general solution of equation (7) is therefore only possible, if $n_{e}(r), f(v),,\left\langle\sigma_{1} v_{e}\right\rangle=f_{i}(r)=f\left(T_{e}\right)$, $\left.<\sigma_{E m} v_{e}\right\rangle=f_{e x}(r)=f_{e x}\left(T_{e}\right)$ are precisely known or have only a weak spatial dependance. Fortunately the latter case is true in PISCES, where the $n_{e}-$ and $T_{e}$-profiles do not reveal a strong (axial) dependance unlike in a tokamak boundary layer, where these profiles change considerably in (radial) direction. Therefore equation (7) can be strongly simplified to:

$$
\phi_{\mathrm{A}}=\frac{4 \pi}{\Gamma}-\mathrm{B}_{\mathrm{tot}} \frac{\left\langle\sigma_{\mathrm{I}} \mathrm{v}_{\mathrm{e}}\right\rangle}{\left\langle\sigma_{\mathrm{Em}} \mathrm{v}_{\mathrm{e}}\right\rangle}
$$

which relates the measured total intensity to the particle flux via the ionization events per emitted photon $\left\langle\sigma v_{e}>/\left(\Gamma<\sigma_{E_{m}} v_{e}>\right)\right.$. The last expression is mainly referred in the literature as $\mathrm{S} / \mathrm{XB}$.

We need this formula in the rearranged form:

$$
\frac{\phi_{\mathrm{A}}}{4 \pi \mathrm{B}_{\text {tot }}}=\frac{\left\langle\sigma_{\mathrm{I}} \mathrm{v}_{\mathrm{e}}\right\rangle}{\Gamma\left\langle\sigma_{\mathrm{Em}} \mathrm{v}_{\mathrm{e}}\right\rangle}
$$

where the ionization events per emitted photon can be determined, if the total number of injected particles $\phi$ and brightness $B_{\text {tot }}$ is known.

In the case of molecules the radiating particles can now not only be ionized within the 
observation volume (as in the case of atoms) but also dissociated or even neutralized. Therefore the cross section $\sigma_{\mathrm{I}}$ has to be replaced by a more general one $\sigma=\sigma_{\mathrm{I}}+\sigma_{\mathrm{D}}+\sigma_{\mathrm{N}}$ (where $\mathrm{D}$ denotes dissociation and $N$ neutralization) and the expression $\left\langle\sigma v_{e}>/\left(\Gamma<\sigma_{E m} v_{e}>\right)\right.$ describes the general loss events per photon, which represents the flux of the molecule or molecular radical per respective photon emitted. By measuring this numter for the molecules injected and photons counted it should then vice versa be possible to obtain spectroscopically numbers for the specific molecular fluxes from edge components in fusion devices.

The OMA in front of the exit slit used (EG \& G model 1460) consisted of a linear array (Stype) of 1024 pixels with a spaving of $25 \mu \mathrm{m}$ and a height of $2.5 \mathrm{~mm}$. These dimensions provided a spectral resolution of $0.15 \AA$ and a total range of $153.6 \dot{A}$ with the grating used. For a spatial recording of the penetration of the molecules and their radicals through the plasma, the OMA was rotated by $90^{\circ}$. The total brightness was then obtained by an integration of the attenuation profile. In this mode the spatial resolution was $0.23 \mathrm{~mm}$ and the total possible detection range $230.4 \mathrm{~mm}$. The spectral resolution was determined by the height of pixels $(2.5 \mathrm{~mm} \equiv 15 \AA)$ as no limiting exit slit could be placed at the position of the array. Therefore the width of the exit slit for the PMT measurements was also chosen to be $2.5 \mathrm{~mm}$ (in cases were this was necessary e.g. broader band structures) in order to be compatible with the OMA measurements.

\section{RESULTS}

All the experiments were carried out using helium as the working gas. The reason for this choice was to avoid possible interference with molecular band emission from the background and the in jected gas. In general, three plasma regimes were chosen for the experiments: High $T_{e}(\approx 30 \mathrm{eV})$, low $\mathrm{n}_{\mathrm{e}}\left(\approx 1 \times 10^{12} / \mathrm{cm}^{3}\right)$; medium $\mathrm{T}_{\mathrm{e}}(\approx 20 \mathrm{eV})$, medium $\mathrm{n}_{\mathrm{e}}\left(\approx 2.5 \times 10^{12} / \mathrm{cm}^{3}\right)$; and low $\mathrm{T}_{\mathrm{e}}(\approx 10 \mathrm{eV})$, high $\mathrm{n}_{\mathrm{e}}\left(\approx 5 \times 10^{12} / \mathrm{cm}^{3}\right)$ in order to simulate three cases of a tokamak boundary plasma. For a characteristic high $\mathrm{T}_{\mathrm{e}}$ - and low $\mathrm{T}_{\mathrm{e}}$-case the radial and axial electron density end temperature profiles were measured by the probes and are shown in figure 3. The plasma column had a width of about 4-6 cm and the electron density and temperature was relatively constant in axial direction except for the last $2 \mathrm{~cm}$ in front of the nozzle in the high temperature case. The reason for this is probably that - especially for lower plasma densities - the "shine-through" of the high energetic, non-Maxwellian electron velocity component is not completely blocked. The existence of such a component for a few discharge conditions may explain some of the peculiarities in the results (see below). 


\section{A. The spectra}

Spectrograms for each gases were taken for two different plasma conditions: $H$ igh $\mathrm{T}_{\mathrm{e}}(\approx 30 \mathrm{eV})$, low $\mathrm{n}_{\mathrm{e}}\left(\approx 1 \times 10^{12} / \mathrm{cm}^{3}\right)$, and low $\mathrm{T}_{e}(\approx 10 \mathrm{eV})$, high $\mathrm{n}_{e}\left(\approx 5 \times 10^{12} / \mathrm{cm}^{3}\right)$ in order to simulate the two extreme cases of a tokamak boundary plasma. The whole spectrum was generally composed out of 15 individual takes; the exposure time for most of these was $\approx 60 \mathrm{sec}$, slightly varying with the changing sensitivity of the film. The occasional appearance of a continuum at longer wavelengths at the bottom of the spectra is a reflection of the emission from the hot $\mathrm{LaB}_{6}$-cathode at the far end of the tube. According to the condition of the nozzle, which tended to be covered by a carbon layer after longer operation of injection, the reflection for this radiation from this irregularly shaped layer could be remarkably different. The gas enters the plasma through the nozzle from the bottom of the spectrogram and can be followed up to $10 \mathrm{~cm}$ through the plasma. Penetration depths of about $2 \mathrm{~cm}$ can in general be qualitatively derived for the molecular species and/or their radicals. The long, non attenuated lines are helium lines, which readily serve as wavelength and deconvolution standards for the instrumental function. This function is somehow wavelength dependent as the $\mathrm{CaF}_{2}-$ prism in front of the entrance slit acts as a dispersive element. As general identification aid concerning photographic recorded spectra the references [1] and [22] were used. Concerning the molecular spectra level numbers and signatures the works from [23] were very helpful.

In this section the general display of the respective spectra will be discussed; for the parts of the spectra, which have been selected for quantitative measurements see section B below. A complete set of the bands, which were identified in the spectra can be found in table 1.

\section{Methane spectra $\left(\mathrm{CH}_{4}\right)$}

Figure $4 a, b$ shows the main features of a hydrocarbon spectrum with a single $C$ in the visible spectral range. The most obvious features are the bands of the $\mathrm{CH}$-radical. First the $4300 \AA$-system $\left(A^{2} \Delta-X^{2} \Pi\right)$, which is degraded to the violet. The $Q-$ head of the $(0,0)$-band is at $4314.2 A$. A linelike feature at $4324 \AA$ is the piled up $Q$-branch of the $(2,2)$-band. And second the $3900 \AA$-system $\left(B^{2} \Sigma-X^{2} \Pi\right)$, which degrades to the red. There are no other bands in this region of the visible spectrum (from the two lowest lying electronic states into the ground state) and therefore these two systems are the most prominent ones.

Lines of the Methylene radical $\left(\mathrm{CH}_{2}\right)$ band could be detected - a wide band between 4500 and $9000 \AA\left(\bar{b}^{1} B_{1}-\bar{a}^{1} A_{1}\right)$ displaying line-like features -, but are barely seen on the spectra (better detectable with the OMA) [24]. Bands of $\mathrm{CH}^{+}$from the Douglas-Herzberg system $\left(\mathrm{A}^{1} \Pi-\mathrm{X}^{1} \Sigma\right)$, which are degraded to the red, could be identified, but the $(0,0)$-band is so strongly blended by the $4300 \AA$-system that the observation of the $(0,1)$-band around $4780 \AA$ should be preferred. Both bands have also already been observed by laser induced fluorescence technique in [25].

Also the atomic lines of hydrogen were found - the product of the dissociation process - , 
whereas lines from singly ionized carbon could hardly be seen on the $\mathrm{CH}_{4}$-spectra taken. It is in addition interesting that the intensity ratio of $\mathrm{H}_{\alpha_{1}, \gamma, \gamma} / \mathrm{CH}$ is growing with the electron temperature, thus indicating that the cross section for producing $\mathrm{H}_{Q, \beta, \gamma}$-radiation from $\mathrm{CH}_{4}$ is smaller than those for $\mathrm{CH}$-band emission for lower temperatures. This has already been found by [26]. The reason for this is obviously the very low lying $A^{2} \Delta$-state.

No explanation we have so far for the fact that ini fig.4a a $C_{2}$-molecular band at $3600 \AA$ seems to be present, as methane should not be able to split into $C_{2}$-molecules. Perhaps carbon, which had been deposited on the nozzle after dissociation from methane has led to the appearance of such features.

\section{Acetplene and ethulene spectra $\left(\mathrm{C}_{2} \underline{\mathrm{H}}_{2} \mathrm{C}_{2} \underline{\mathrm{H}}_{4}\right)$}

Figure $5 a, b$ and $6 a, b$ show the main features of a hydrocarbon spectrum with an additional $C$ in the visible spectral range. These are: a) the Deslandres-d'Azambuja system $\left(c^{1} \Pi_{g}-b^{1} \Pi_{u}\right)$ from $\approx 4000 \AA$ and $b$ ) the Swan system $\left(A^{3} \Pi_{g}-X{ }^{3} \Pi_{u}\right)$ from $\approx 6200 \AA$ down to the violet. Particularly the latter system has such a remarkable structure that it can easily be identified. Lines from singly ionized carbon can now clearly be seen, especially for the higher temperature cases, which is the result of the larger $\mathrm{C} / \mathrm{H}$-ratio. The penetration depth seerns to be slightly smaller for these molecules than for methane because of their larger masses.

\section{Carbon exide spectra $\left(\mathrm{CO}, \mathrm{CO}_{2} \mathrm{~L}\right.$}

These spectra are the most structured of the ones taken ( $F ;, 7 a, b$ and $8 a, b)$. And although the $\mathrm{CO}$ molecule has been investigated for more than a century, it 'ill belongs to the most intensively studied diatomic molecules. The results of investigations of its sf :ctrum and energetic structure have been collected by [27], [28], and [29]. But even today new bands $n$ the emission spectrum of $C O$ have been detected [30]. There are also remarkable differences between the low and high temperature cases. Therefore it is not astonishing that long available evidence of the existence of $\mathrm{CO}$ bands in tokamaklimiter spectra were not identified as such [1].

In the long wavelength range around $6000 \AA$ the low temperature $C O$ spectrum is mainly governed by four bands: the Triplet Bands $\left(d^{3} \Delta-a^{3} \Pi\right)$, the Asundi bands $\left(a^{3} \Sigma-a^{3} \Pi\right)$, the Angström system $\left(B^{1} \Sigma-A^{1} \Pi\right)$, and the Herman bands $\left(e^{3} \Sigma^{-}-a^{3} \Pi\right)$. These four bands overlap partly and even for experts in molecular spectroscopy it is not always easy to distinguish them perfectly as demonstrated in controversial publications [31]. In the direction to shorter wavelengths the Third Positive Bands $\left(b^{3} \Sigma-a^{3} \Pi\right)$ and the $C O$ flame bands $\left({ }^{1} B_{2}-X^{1} \Sigma^{+}\right)$are added.

The high temperature case reveals a somehow simpler picture. Now the most prominent throughout the whole spectrum is the so called Comet tail system $\left(A^{2} \Pi-X^{2} \Sigma\right)$ of $C O^{+}$. As $C O$ is a rather stable molecule, it also shows an intensive molecular ion spectrum. The Comet tail system is characterized by two strong $R$-heads with corresponding $Q$-heads lying from 5 to $1.5 \AA$ to the rad of 
the $\mathrm{R}$-heads. The bands are degraded to the red. A weaker system of $\mathrm{CO}^{+}$, the Baldet-Johnson system $\left(B^{2} \Sigma-A^{2} \Pi\right)$ is now also visible in the blue part of the spectrum. Particularly remarkable is the fact that the red part of the spectrum is now completely governed by the comet tail system of $\mathrm{CO}^{+}$, whereas the Triplet Bands, the Asundi bands, and the Angstrom system practically disappeared. This strungly changing display of the CD-spectrum leads to the different spectra, which are published in the literature and makes identifications partly rather difficult.

Also the lines of singly ionized oxygen and carbon can be, detected - of course better in the high temperature case. It is also astonishing that the origin of these lines is directly at the front of the nozzle, which could lead to the assumption that the ions originate directiy from the molecule without an intermediate atomic step. An exotic band in the $\mathrm{CO}$ spectrum, which obviously always seems to appear are the bands $\lambda \lambda 2883$ and $\lambda \lambda 2896\left(A^{2} \Sigma^{+}-X^{2} \Pi\right)$ of $\mathrm{CO}_{2}{ }^{+}$around $2990 \AA$. These were also found in our CO spectra.

The $\mathrm{CO}_{2}$-spectra are in wide parts identically with the CO-spectra - especially for the high temperature case -, which shows that the break-up process nearly completely includes the formation of a CO${ }^{(+)}$-molecule. Only the CO-flame bands $\left({ }^{1} \mathrm{~B}_{2}-\mathrm{X}^{1} \Sigma^{+}\right)$are slightly better visible and a $\mathrm{CO}_{2}{ }^{+}$band, the Fox, Duffendack and Barker's system $\left(A^{2} \Pi-X^{2} \Pi\right)$ additionally appears. But these facts make it rather difficult to distinguish spectroscopically between a $\mathrm{CO}$ - and a $\mathrm{CO}_{2}$-molecule, if the bands are only weakly visible and other strong lines or bands are interfering.

\section{B. Absolute intensity/flux calibrations}

In order to determine the ratio of the total loss events by the number of emitted photons $(\mathrm{S} / \mathrm{XB})$ for different electron temperatures of the working gas according to equ. (9), the integrated absolute brightness for a number of bands and lines was measured as a function of the of the molecular influx (acrording to equ. (3a)). This total influx was distributed over a (vertical) length of $0.95 \mathrm{~cm}$ (of the nozzle) so that the total particle number per sec was practically identical with the number of molecules $/(\sec \times \mathrm{cm}(! !))$. Fig 9 shows the specific lines and bands, which have been used for these measurements. Although it was tried to use normally the brightest band of the respective molecule or one of its radical in the vicible spectral range, the choice was occasionally (particularly for $\mathrm{CO}$ ) influenced by the possible observability in a tokamak limiter spectrum, where strong $(2 r$ ' on and oxygen ion lines are always present in the foreground. The hatched arcas always de. ine the wavelength range of $15 \AA$ (exit slit wiath $=2.5 \mathrm{~mm}$, see II.C), which was used as integration in the case of a molecular band, and which can also be easily covered by an interference filter with a similar halfwidth.

For the measurement of the $C H$-radical the $(0,0)$-band of the $\left(A^{2} \Delta-X^{2} \Pi\right)$-transition at 4315 $\AA$ was used (Fig.9a). The hatched area covers about completely the whole Q-branch, whereas the Pbranch unfortunately interferes partly with the $(0,0)$-band of the $\left(A^{1} \Pi-X^{1} \Sigma\right)$ of the $\mathrm{CH}^{+}$. Therefore 
for the observation of the latter the $(0,1)$-band of the same transition at $4780 \AA$ is of much better use (Fig.9b). For the $C_{2}$-molecuie the $(0,0)$-band of the $\left(A^{3} \Pi_{g}-X^{3} \Pi_{u}\right)$-transition at $5165 \AA$ proved to be the best one (Fig.9c); occasionally its $(1,2)$-transition at $5585 \AA$ was used. For $\mathrm{CH}_{2}$ the region around $6330 \AA$ was used as a rather arbitrary choice for the observation of the $\left(\bar{b}^{1} B_{1}-\tilde{a}^{1} A_{1}\right)$-transition (Fig.9d). For $\mathrm{CO}$ a region around $6072 \AA$ was selected, were a band of the Triplet band $\left(d^{3} \Delta-a^{3} \Pi\right)$ offered the most undisturbed possibility for the observation of $\mathrm{CO}$ (Fig.9e). For $\mathrm{CO}^{+}$a band of the comet tail system $\left(A^{2} \Pi-X^{2} \Sigma\right)$ at $5505 \AA$ proved to be the best one (Fig. 9f). Beside the molecular bands the $\mathrm{H}^{0}$ - and CII-lines at 6563 and $6582 \AA$ respectively (Fig. $9 \mathrm{~g}$ ), the Ol-lines at $8446 \AA$, and the brightest of the CI-lines at $9095 \AA$ were observed.

For all lines $u r$ bands given photoelectric measurements were made for at least two different m'slecular flux rates $\left(\approx 3.5 \times 10^{17} /(\mathrm{sec} \times \mathrm{cm})\right.$ and $\approx 1.0 \times 10^{18} /(\mathrm{sec} \times \mathrm{cm})$, but for some selected ones for a whole flux range (from $\approx 2.0 \times 10^{16} /\left(\mathrm{sec} \times \mathrm{cm}\right.$ ) to $\approx 5.0 \times 10^{18} /(\mathrm{sec} \times \mathrm{cm}$ )). For the lower fluxes the resulting molecular density is $\approx 0.8 \times 10^{12}-1.1 \times 10^{13} / \mathrm{cm}^{3}$, which is in the order of the electron density, for the higher fluxes, however, this density is with $\approx 4.5 \times 10^{13}-2.0 \times 10^{14} / \mathrm{cm}^{3}$ an order of magnitude higher than $n_{e}$, but still in the range as expected from a surface in $\geqslant$ tokamak. Therefore some deviations from the measured $T_{e}$ might be expected for the latter case, although for all cases the electron temperature was measured with the molecular stream on by the probes $\approx 1 \mathrm{~cm}$ in front of the nozzle. As for the low temperatures the electron density is always high $\left(\approx 6 \times 10^{12} / \mathrm{cm}^{3}\right)$, the disturbing effect is certainly a minimum, but that might be different for the high temperature cases.

Unfortunately it was practically not possible to separate temperature and density dependent effects (if there were any on the latter at all) on the photon emission from each other, as $T_{e}$ and $n_{e}$ of the discharge could not be varied independently. Fig. 10 illustrates the behavior of the $\mathrm{CH}$-band emission for a fixed $\mathrm{CH}_{4}$-flux for discharges with different $\left(\mathrm{T}_{e}, \mathrm{n}_{e}\right)$-parameters. The change of the photon emission by a factor of 3 is accompanired by the same factor in the $T_{e}$-change, whereas a factor of more than 6 is needed for $n_{e}$. Therefore the electron temperature of the discharge is obviously a much more sensitive parameter for the photon emission than the density.

Absolute intensity/flux measurements were made for four molecular species: $\mathrm{CH}_{4}, \mathrm{C}_{2} \mathrm{H}_{2}$, $\mathrm{C}_{2} \mathrm{H}_{4}$, and $\mathrm{CO}$ and the results are displayed in the figures 11 to 14 . For test purposes also $\mathrm{D}_{2}$ was used as injected gas. The diagrams in the left column of these figures show the dependence of the measured integrated photon intensity for one wavelength or wavelength-band on the molecular influx for three different $\mathrm{T}_{\mathrm{e}}(\approx 10 \mathrm{eV}, \approx 25 \mathrm{eV}, \approx 35 \mathrm{eV}$ ) as parameters. One can notice already that no major deviations occur from the linear dependance of injected particles to the detected photons. The ordinate was then converted with the help of equation (3a) into loss events per photon ( $S / X B$ ), and the resulting graphs can be found in the right columns. If the amount of in jected particles would not play any role at all, one would expect three perfectly straight lines parallel to the abscissa. This is not completely true (yet an excellent example of such a behavior is shown in fig.12f), kut stronger deviations can practically first be noticed for fluxes greater than $10^{18} /(\mathrm{sec} \times \mathrm{cm})$. The reason for the occasionally 
several "ups" and "downs" in these lines - they are not within the errors - is not yet understood; a change in the population of a molecular/atomic level by a change in the exciting collision mechanism maybe one probable explanation. The latter graphs were replottet with $T_{\mathbf{e}}$ on the abscissa for two or three selected flux rates, varying from $\approx 3.5 \times 10^{17} /\left(\mathrm{sec} \times \mathrm{cm}\right.$ ) to $\approx 1.0 \times 10^{18} /(\mathrm{sec} \times \mathrm{cm}$ ) (see above). Some examples of these plots are collected in the figures 15 to 18 for the individual gases injected together with some additional bands or lines, which are not displayed in the foregoing figures. By choosing different molecular fluxes as parameters one may produce additional graphs $\mathrm{S} / \mathrm{X} B$.

An interesting comparison of the behavior of the $\mathrm{C}_{2} / \mathrm{CH}$ band intensity ratio for acetylene and ethylene can be demonstrated in figure 19. This ratio is systematically larger for acetylene for all electron temperature ranges, which proves in an impressive way the stronger force of the carbon triple bond in $\mathrm{C}_{2} \mathrm{H}_{2}$ versus the double bond in $\mathrm{C}_{2} \mathrm{H}_{4}$.

In order to strengthen also the confidence in the ahsolute numbers measured for the loss events per photon, the carbon containing molecules were replaced by deuterium molecules $\left(D_{2}\right)$. For this gas experimental values concerning loss events per $\mathrm{H}_{\alpha}$-photon are already available, obtained in similar types of experiments or even in tokamaks, where $D_{2}$ had been puffed through a limiter into the plasma boundary layer ([32] or [33]). We preferred deuterium for these kind of experiments, as its mean free path is shorter than that for $\mathrm{H}_{2}$ because of its larger mass. The results of these measurements are displayed in figure 20 . The numbers obtained (loss events per $D_{\alpha}$-photon $\approx 140$ ) are about a factor of 2.5 larger than those cited in [32] $(\approx 52)$. But this difference is not surprising and can be explained by the fact that in PISCES the integration does not cover the whole attenuation length in the case of deuterium atoms, which is in the order of $80 \mathrm{~cm}$ (see fig.20a) and will account for a similar correction fictor. Having this in mind, the photons are primarily produced by dissociative excitation and the number for this process is given in [33] as about 100. Therefore, no strong systematic errors should be involved in the respective measurements for the carbon containing molecules, where the respective attenuation lengths are in the $\mathrm{cm}$-range.

\section{Axial beam attenuation measurements}

For these kind of measurements - a spatial recording of the penetration of the molecules and their radicals through the plasma - the OMA was rotated by $90^{\circ}$ so that the total possible detection range was theoretically $230.4 \mathrm{~mm}$, but it was practically limited by the aperture of the window $(\varnothing=$ $100 \mathrm{~mm}$ ). The linear conversion factor was $2.25 \mathrm{~cm}$ for 100 pixel. As no limiting exit slit could be placed at the position of the array, the spectral resolution was determined only by the height of pixels $(2.5 \mathrm{~mm} \equiv 15 \AA)$. This OMA measurements. This restriction in the spectral resolution was e.g. the reason why the lines from the $(0,0)$-band of the Douglas-Herzberg system $\left(A^{1} \Pi-X^{1} \Sigma\right)$ for $\mathrm{CH}^{+}$could not be observed, because they are strongly blended by the $4300 \AA$-system of $\mathrm{CH}$, and the observation of the $(0,1)$-band around $4780 \AA$ was preferred instead. 
Beam attenuation measurements in the axial direction of the discharge were made for the molecular species $\mathrm{CH}_{4}, \mathrm{C}_{2} \mathrm{H}_{2}, \mathrm{C}_{2} \mathrm{H}_{4}$, and $\mathrm{CO}$ for three different $\left(\mathrm{T}_{e}, \mathrm{n}_{e}\right)$-conditions and two molecular fluxes. Thu results are collected in the figures 21 to 35 . The integration time for the individual measurements was between 10 and $60 \mathrm{sec}$ depending on the amount of flux and/or the discharge conditions. The traces shown in the figures are already reduced by the individual background (recorded without in jection for the same wavelength range and the same integration time) and deconvoluted with the apparatus function obtained via discharge (He)-lines in the same wavelength region (see section III.A). A correction for a possible beam dilution was not applied and is probably only necessary for atoms with a long penetration depth, which could escape the discharge column without having been ionized (e.g. $\mathrm{H}^{0}$ or $\mathrm{D}^{0}$ (see III,B). Put model calculations, which try to simulate the break-up and the path of the resulting radicals and atoms should have in mind the injection geometry (a $1 \mathrm{~cm}$ long slit in the vertical direction) and the optical integration along the line of sight!

In order to test the influence of the surrounding chamber walls on a possible flux of reflected particles, which would distort the measured profiles, the diameter of the discharge was varied and looked for a possible change in the attenuation profile. No change was detected during these tests within the error bars so that such an influence could be exciuded.

\section{DISCUSSION}

If one compares the spectra taken in PISCES-A with those published in [1], which were recorded during tokamak operation from one of the main (carbon)limiters, a few of the so far unidentified bands can now be uniquely attributed. Although in the latter reference the $4300 \AA$-system $\left(A^{2} \Delta-X^{2} \Pi\right)$ of the $C D$-radical was already identified, its strange behavior to the violet (a second hump at $4220 \AA$ ) can now be explained by the appearance of the Douglas-Herzberg system ( $A^{1} \Pi$ $\mathrm{X}^{1} \Sigma$ ) from $C D^{+}$. (There is in fact a slight difference in the $C D$ - and $C H$-spectra but the lines are only shifted by a few Angstroms and the general appearance is unchanged.) Traces of $\mathrm{C}_{2}$-bands are also observable for lower electron temperatures $(\approx 10 \mathrm{eV})$, particularly the $(0,0)$-band of the $\left(A^{3} \Pi_{g}\right.$ $\left.X^{3} \Pi_{u}\right)$-transition at $5165 \AA$ and the $(1,2)$-transition at $5585 \AA$ of the Swan system. There is a strong suspicion that the carbon limiter spectra also show higher order carbon molecule bands from $C_{3,4}, .$. which display several line-like features (which in reality are whole rotational band structures), but as no such $\mathrm{C}$-containing were injected and the information found in the literature is very scarce, no identification for these sorts of molecules could unfortunately be made.

It was suspected that, beside hydrocarbons, carbonoxides seem to play a mayor role in the transport of carbon and oxygen in the boundary layer of a tokamak. This is now also spectroscopically confirmed by the fact that vadoubtedly molecular bands of $\mathrm{CO}$ and $\mathrm{CO}^{+}$could be identified in tne 
specira of [1] by comparison with those obtained in PISCES-A for injected carbonoxides. Particularly the Triplet Bands $\left(d^{3} \Delta-a^{3} \Pi\right)$ and the Asundi bands $\left(a^{3} \Sigma-a^{3} \Pi\right)$ are strongly dominant in the region between 6000 and $6500 \AA$. Originally it had been assumed that the lines found there wouiu belong to the molecular deuterium spectrum. One can indeed find coincidences with the spectra from the latter molecule, but the recorded tokamak spectra reveal obviously much more similarities with those from carbonoxides in that spectral range. Between 5400 and $5800 \AA$ the bands $\left(A^{2} \Pi-X^{2} \Sigma\right)$ from the comet tail system of $\mathrm{CO}^{+}$are now clearly visible. This identification would not have been so easily possible than by the PISCES spectra.

In order to calibrate the intensity of several bands and lines, the measured loss events per emitted photon as a function of electru. temperature- as shown in the figures 15 to 18 - can be used. It should be noted here that for spectral lines from atoms and ions this ratio is generally a monotonously growing function of $T_{e}$ in the range between $1 \mathrm{eV}$ and $200 \mathrm{eV}$ (see e.g. [20]). However, in the case of molecules there can be a minimum, which is the result of a necessary dissociation process (for this see e.g. [33]). A fortunate conclusion of this behavior is that in our case this ratio can of ten be treated as relatively constant (see eg. $\mathrm{CH}$-band for $\mathrm{CH}_{4}$, fig.15a). For $\mathrm{H}_{\alpha}$ even a decreasing function was measured (see fig. 16b). On the other hand the $C O$ bands at 4827 and $6072 \AA$ (see fig.18c,d) show the same functional dependance as those for atoms and ions (as actually expected). The appearance of a remarkable minimum in some of the S/XB-graphs in figs. 11-20 can be an additional effect of a finite particle confinement time for the neutrals [34]. This would have, of course, a very pronounced influence in the case of hydrogen or deuterium.

So far no known calculations exist in order to compare them with our measured values. There are experimental excitation cross sections for the $4300 \AA$-system $\left(A^{2} \Delta-X^{2} \Pi\right)$ of the $C H$-radical and $H_{\alpha}$ for a number of hydrocarbons (inclusive our injected ones) in ref [26], [35] and [36]. There an electron beam was sent through a hydrocarbon gas with known density, and the emitted radiation was detected by an absolutely calibrated spectrometer. As the electron density in these experiments was very low (in the $10^{7} / \mathrm{cm}^{-3}$ range), the measured cross sections are perhaps not directly comparable, because multistep processes, which are needed to produce a $\mathrm{CH}$-radical, are relatively unlikely. But this has to be clarified by a more intense analysis of the differences between the experiments. Nevertheless, as these were the only available numbers in our case, they were used in combination with the loss events taken from [12] to calculate the loss events per photon emission (S/XB) for some of our hydrocarbon cases. Unfortunately no comparison of this kind could be made for the carbon oxides. For methane these values are included in the graphs for $\mathrm{CH}$ and $\mathrm{H}_{\alpha}$ (fig. 15a,b) and agree surprisingly well with our experimental ones. For the other hydrocarbons this agreement is not so expressed.

The measurements of the penetration depths (fig. 20-35) may serve as an experimental background in order to test Monte Carlo codes, which try to solve the complete breakup process, and the rates used therein [12]. On the other hand, when doing this, several experimental peculiarities should be obeyed. The B-field in PISCES-A is parallel to the direction of injection and the electron 
distribution function consists occasionally out of two components, the hotter one which is not a Maxwellian one. This and additional plasma effects (e.g. the trapping of ions in front of the nozzle), could be a determining factor in the spatial dependence of the ionized species. Therefore it is recommended to repeat similar injection experiments in tokamak machines, where the B-field has a different direction.

But the following conclusions concerning the fueling efficiency of a tokamak discharge by hydrocarbons may already be drawn out of our experiments: The far largest penetration depth for all products was measured for $\mathrm{CH}_{4}$ ! In the case of $\mathrm{C}_{2} \mathrm{H}_{2}$ and even more for $\mathrm{C}_{2} \mathrm{H}_{4}$ a practical complete attenuation for all products occurs within a few centimeters (Compare e.g. fig. 21 a and 25a for the CHradical). This means that other hydrocarbons than methane play a relatively minor role in the fueling. The onset of the hydrogen .. and very of ten also the CII-production occurs very near the injection nozzle. This fact leads to the suspicion that some species - and even ions - are produced rignt away from the origin of the molecules and not only at the end of a long breakup chain.

\section{ACKNOWLEDGMENT}

One of us (A.P.) would like to thank the people from the PISCES team for their hospitality, excellent support in running the machine and providing the necessary experimental equipment. 


\section{REFERENCES}

[1] A.Pospieszczyk, H.L.Bay, P.Bogen, H.Hartwig, E.Hintz, L.Könen, G.G.Ross, D.Rusbüldt, U.Samm, and B.Schweer J.Nucl.Mater. 145-147 (1987), 574

[2] U.Samm, H.L.Bay, P.Bogen, H.Hartwig, E.Hintz, K.Hothker, Y.T.Lie, A.Pospieszczyk, G.G.Ross, D.Rusbüldt and B.Schweer, Plasma Phys. Contr. Fus, 29 (1987) 1321

[3] K.H.Behringer, Journ.Nucl.Mater. 145-147 (1987) 145

[4] K.H.Behringer et al., Proc. $11^{\text {th }}$ Europ. Conf. Contr. Fus. Plasma. Phys., Vol.II, Aachen(1983), 467

[5] G.Fussmann and the ASDFX-team, Journ.Nucl.Mater., 145-147 (1987) 96

[6] C.S.Pitcher, G.M.McCracken, P.C.Stangeby, J.Allen, S.J.Fielding, D.H.J.Goodall and G.F.Matthews, Journ.Nucl.Mater., 145-157 (1987) 539

[7] W.D.Langer and A.B.Ehrhardt, Journ.Nucl.Mater., 162-164 (1989) 329

[8] K.H.Behringer, P.G.Carolan, B.Denne, G.Decker, W.Engelhardt, M.J.Forrest, R.Gill, N.Gottardi, N.C.Hawkes, E.Källne, H.Krause, G.Magyar, M.Mansfield, F.Mast, P.Morgan, N.J.Peacock, M.F.Stamp, H.P.Summers, Nuclear Fusion, 26 (1986) 751

[9] R.W.B.Pearse and A.G.Gaydon, The identification of molecular spectra, Ed. Chapman and Hall, J. Wiley \& Sons, Inc., New York (1960)

[10] W.D.Langer, Nucl.Fus., 22 (1982) 751

[11] W.D.Langer and A.B.Ehrhardt, Fus.Techn, 15 (1989) 118

[12] A.B.Ehrhardt and W.D.Langer, Report PPPL-2477, Princeton Univ., 1987

[13] D.Rapp and P.Englander-Golden, J.Chem.Phys., 43 (1965) 1464

[14] O.J.Orient and S.K.Srivastava, J.Phys.B: At.Mol.Phys., 20 (1987) 3923

[15] V.Philipps, E.Vietzke and M.Erdweg, Journ.Nucl.Mater., 162-164 (1987) 551

[16] D.M.Goebel, G.A.Campbell, R.W.Conn., J.Nucl.Mat., 121 (1984) 277

[17] D.M.Goebel, and R.W.Conn, J.Nucl.Mat., $128 \& 129$ (1984) 249

[18] D.M.Goebel, Y.Hirooka, T.A.Sketchley, Rev.Sci.Instr., 56 (1985) 1717

[19] PISCES-Team, Report UCLA-PPG-1247, May 1989, and

R.D.Lehmer, B. LaBombard, R.W.Conn, Report UCLA-PPG-1228, April, 1989

[20] M.F.Stamp, K.H.Behringer, M.J.Forrest, P.D.Morgan, H.P.Summers, Proc. $14^{\text {th }}$ Europ. Conf. Contr. Fus. Plasma Phys., Budapest (Hungary), 1985, Vol.II, 539 
[21] .Bogen, H.Hartwig, E.Hintz, K.Höthker, Y.T.Lie, A.Pospieszczyk, U.Samm and W.Bieger, J. Nucl. Mat., 128 \& 129 (1994) 157

[22] A.G.Gaydon, The spectroscopy of flames, Ed. Chapman and Hall, London (1957)

[23] G.Herzberg, Molecular spectra and molecular structure, Vol.I,II,III, D.van Nostrand, Princeton

[24] G.ß̊.Möhlmann and F.J.de Heer, Chem.Phys.Lett, 43 (1976) 2.36

[25] B.H.Mahan and A.O'Keefe, Chem.Phys., 69 (1982) 35

[26] G.R.Möhlmann and F.J.de Heer, Chemical Physics, 19 (1977), 233

[27] P.H.Krupenie, The band spectrum of carbon monoxide, (Nat. Bur. Stand., Washington, 1966)

[28] S.G.Tilford and J.D.Simmons, J.Phys.Chem.Ref.Data, 1 (1972) 147

[29] K.P.Huber and G. Herzberg, Molecular spectra and molecular structure, Vol.4, Constants of diatomic molecules (Van Nostrand-Reinhold, New York, 1979)

[30] R.Kepa, Chem.Phys., 110 (1986) 12?

[31] H.A.van Sprang, G.R.Möhlmann and F.J.de Heer, Chem.Phys., 24 (1977) 429

[32] C.S.Pitcher, PhD-thesis, University of Toronto, Inst. for Aerospace Studies, Canada (1987), Chapter 9.

[33] D.H.McNeill, Journ.Nucl.Mater., 162-164 (1989), 476

[34] K.Behringer, private communication

[35] J.F.Aarts, C.I.M.Beenakker and F.J. de Heer, Physica 53 (1971) 32

[36] C.I.M.Beenakker and F.J.de Heer, Chem.Phys., 7 (1975) 130 


\section{FIGURE CAPTIONS}

Fig.1 Schematic experimental arrangement.

Fig.2 Observation geometry

Fig.3 Radial[ $x]$ and axial[y] electron density and temperature profiles measured by the scanning probe for a characteristic high(a) $\mathrm{T}_{e}$ - and low(b) $\mathrm{T}_{e}$-case. $V_{i}$ floating potential, $\Phi_{\mathrm{p}}$ : plasma potential. The $O$ denotes the calibration point from a fixed Langmuir probe. $T_{e}(x, y)$ is cierived via $\alpha T_{e}=\Phi_{p}-V_{f}$.

Fig.4 $\mathrm{CH}_{4}$ (methane)-spectrum for:

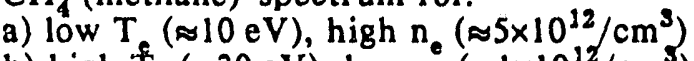

b) high $f_{e}(\approx 30 \mathrm{eV})$, low $\mathrm{n}_{\mathrm{e}}\left(\approx 1 \times 10^{12} / \mathrm{cm}^{3}\right)$

Fig.5 $\mathrm{C}_{2} \mathrm{H}_{2}$ (acetylene)-spectrum for:

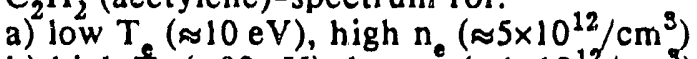

b) high $\mathrm{f}_{\mathrm{e}}(\approx 30 \mathrm{eV})$, low $\mathrm{n}_{\mathrm{e}}\left(\approx 1 \times 10^{12} / \mathrm{cm}^{3}\right)$

Fig.6 $\mathrm{C}_{2} \mathrm{H}_{4}$ (ethylene)-spectrum for:

a) low $\mathrm{T}_{\mathrm{f}}(\approx 10 \mathrm{eV})$, high $\mathrm{n}_{\mathrm{e}}\left(\approx 5 \times 10^{12} / \mathrm{cm}^{3}\right)$

b) high $\mathrm{f}_{\mathrm{e}}(\approx 30 \mathrm{eV})$, low $\mathrm{n}_{\mathrm{e}}\left(\approx 1 \times 10^{12} / \mathrm{cm}^{3}\right)$

Fig.7 $C O$ (carbonmonoxide)-spectrum for:

b) high $\mathrm{f}_{\mathrm{e}}(\approx 30 \mathrm{eV})$, low $\mathrm{n}_{\mathrm{e}}\left(\approx 1 \times 10^{12} / \mathrm{cm}^{3}\right)$

Fig.8 $\mathrm{CO}_{2}$ (carbondioxide)-spectrum for:

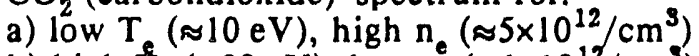

b) high $t_{e}(\approx 30 \mathrm{eV})$, low $\mathrm{n}_{\mathrm{e}}\left(\approx 1 \times 10^{12} / \mathrm{cm}^{3}\right)$

Fig.9 Specific bands and lines, which have been used for absolute intensity/flux calibration measurements. The hatched areas define the wavelength range of $15 \AA$ (exit slit width $=2.5 \mathrm{~mm}$ ), which was used as integration in the case of a molecular band.

a) $\mathrm{CH}:(0,0)$-band of the $\left(\mathrm{A}^{2} \Delta-\mathrm{X}^{2} \Pi\right)$-transition

b) $\mathrm{CH}^{+}:(0,1)$-band of the $\left(\mathrm{A}^{1} \Pi-\mathrm{X}^{1} \Sigma\right)$-transition

c) $C_{2}:(0,0)$-band of the $\left(A^{3} \Pi_{g}-X^{3} \Pi_{u}\right)$-transition (Swan band)

d) $\mathrm{CH}_{2}:\left(\mathrm{b}^{1} \mathrm{~B}_{1}-\tilde{\mathrm{a}}^{-1} \mathrm{~A}_{1}\right)$-transition

e) $C O^{2}:\left(d^{3} \Delta-a^{3} \Pi\right)$-transition (Triplet band)

f) $\mathrm{CO}^{+}:\left(\mathrm{A}^{2} \mathrm{II}-\mathrm{X}^{2} \Sigma\right)$-transition (comet tail band)

g) $\mathrm{H}, \mathrm{CII}: \mathrm{H}_{\alpha}(\lambda=6563 \AA), \mathrm{CII}(\lambda=6578 \AA$ and $6582 \AA)$

h) $\mathrm{CI}: \lambda=9095 \AA$

Fig.10 $\mathrm{CH}$-band emission for a fixed $\mathrm{CH}_{4}$-flux $\left(9.6 \times 10^{17} /(\mathrm{sec} \times \mathrm{cm})\right)$ for discharges with different $\left(T_{e}, n_{e}\right)$-parameters.

a) $\mathrm{CH}$-signal vs electron density

b) $\mathrm{CH}$-signal vs electron temperature

For figures $11-14$ the following definitions are valid:

Left column: integrated photon intensity for one wavelength(band) for different $T_{e}$ as parameters.

Right column: loss events per photon $((S / X B)$ acc. to equ. 9) vs the molecular influx for the same measurements. 
The symbols represent runs with $\bullet 0 \approx 10 \mathrm{eV}, \square \approx 25 \mathrm{eV}$, and $\square \approx 35-40 \mathrm{eV}$ electron temperatures. (Note exceptions for $12 \mathrm{~d}, \mathrm{f}$ and $14 \mathrm{~d}$ )

Fig.11 $\mathrm{CH}_{1}$ (methane):

a),b): $\mathrm{CH}$-band (see fig.9a); c),d): $\mathrm{H}_{\alpha}$ (see fig.9g)

Fig.12 $\quad \mathrm{C}_{2} \mathrm{H}_{2}$ (acetylene):

a),b): $\mathrm{CH}$-band (see fig.9a); c),d): $\mathrm{H}_{\alpha}$ (see fig.9g); e),f): $\mathrm{C}_{2}$-band (see fig.9c)

d): $\approx 10 \mathrm{eV}, \square \approx 25 \mathrm{eV}$, and $\approx \approx 35-40 \mathrm{eV}$ electron temperatures

f): $\square \approx 10 \mathrm{eV}, \diamond \approx 25 \mathrm{eV}$, and $\square \approx 35-40 \mathrm{eV}$ electron temperatures

Fig.13 $\mathrm{C}_{2} \mathrm{H}_{4}$ (ethylene):

a), b): CH-band (see fig.9a); c),d): $\mathrm{H}_{\alpha}$ (see fig.9g); e),f): $\mathrm{C}_{2}$-band (see fig.9c)

Fig.14 CO (carbonmonoxide):

a),b): CO-band (see fig.9e); c),d): OI $(\lambda=8446 \AA)$

d): $\square \approx 10 \mathrm{eV}, \sim \approx 25 \mathrm{eV}$, and $\square \approx 35-40 \mathrm{eV}$ electron temperatures

Fig.15 $\quad \mathrm{CH}_{4}$ (methane):

loss events per photon (acc. to equ. 9) vs electron temperature for one or two molecular fluxes. The points denoted by "Theory" represent calculated values using excitation and ionization cross section from published data (see text).

Fig.16 $\mathrm{C}_{2} \mathrm{H}_{2}$ (acetylene):

loss events per photon (acc. to equ. 9) vs electron temperature for two or three molecular fluxes.

Fig.17 $\quad \mathrm{C}_{2} \mathrm{H}_{1}$ (ethylene):

loss events per photon (acc. to equ. 9) vs electron temperature for two or three molecular fluxes.

Fip.18 CO (carbonmonoxide):

loss events per photon (acc. to equ. 9) vs electron temperature for two molecular fluxes.

Fig.19 $\mathrm{C}_{2} / \mathrm{CH}$ band intensity ratio for acetylene and ethylene as a function of molecular influx. For the symbols see figs.11-14

Fig.20 a) attenuation of a $D_{2}$-beam in the light of $D_{\alpha}$ and of a $D_{2}$-line $(\lambda=6150 \AA)$

b) ionizations per $D_{\alpha}$-photon as a function of electron temperature

Beam attenuation measurements in the axial direction for different molecular species in the light of the different break-up products.

The following figures are for $\mathrm{CH}_{\mathrm{g}}$ and the individual traces are:

a) $\mathrm{CI}$ (fig.9h), b) $\mathrm{CII}$ (fig.9g), c) $\mathrm{H}^{f}$ (fig.9g), d) $\mathrm{CH}_{2}$ (fig.9d), e) $\mathrm{CH}^{+}$(fig 9b), f) $\mathrm{CH}$ (fig.9a)

Fig.21 discharge condition: $T_{e}=44 \mathrm{eV}, n_{e}=1.64 \times 10^{12} / \mathrm{cm}^{3}$

Fig.22 discharge condition: $T_{e}=27 \mathrm{eV}, \mathrm{n}_{\mathrm{e}}=1.70 \times 10^{12} / \mathrm{cm}^{3}$

Fig.23 discharge condition: $T_{e}=9.7 \mathrm{eV}, \mathrm{n}_{e}=3.94 \times 10^{12} / \mathrm{cm}^{3}$ 
Fli.24 discharge condition: $\mathrm{T}_{0}=8.0 \mathrm{eV}, \mathrm{n}_{e}=2.48 \times 10^{12} / \mathrm{cm}^{3}\left(3.18 \times 10^{17} /(\mathrm{cm} \times \mathrm{sec})\right.$

Fig.25 discharge condition: as fig. 24 but $2.03 \times 10^{18} /(\mathrm{cm} \times \mathrm{sec})$

Fig.26 discharge condition: $\mathrm{T}_{\mathrm{e}}=8.1 \mathrm{eV}, \mathrm{n}_{0}=5.17 \times 10^{12} / \mathrm{cm}^{3}\left(3.18 \times 10^{17} /(\mathrm{cm} \times \mathrm{sec})\right.$

Fig. 27 discharge condition: as fig. 26 but $2.03 \times 10^{18} /(\mathrm{cm} \times \mathrm{sec})$

The following figures are for $\mathrm{C}_{2} \mathrm{H}_{2}$ and the individual traces are:

a) $\mathrm{Cl}(\mathrm{fig} .9 \mathrm{~h}), \mathrm{b}) \mathrm{CII}(\mathrm{fig} .9 \mathrm{~g}), \mathrm{c}) \mathrm{H}^{\circ}(\mathrm{fig} .9 \mathrm{~g})$, d) $\mathrm{C}_{2}(\lambda=5582 \AA)$, e) $\left.\mathrm{C}_{2}(\mathrm{fig} .9 \mathrm{c}), \mathrm{f}\right) \mathrm{CH}^{+}$ (fig.9b), g) $\mathrm{CH}$ (fig.9a)

Fig.28 discharge condition: $T_{e}=43 \mathrm{eV}, \mathrm{n}_{\mathbf{e}}=1.77 \times 10^{12} / \mathrm{cm}^{3}\left(1.27 \times 10^{18} /(\mathrm{cm} \times \mathrm{sec})\right.$

Fig.29 discharge condition: as fig.28 but $2.61 \times 10^{18} /(\mathrm{cm} \times \mathrm{sec})$

Fig.30 discharge condition: $\mathrm{T}_{\mathrm{e}}=12 \mathrm{eV}, \mathrm{n}_{\mathrm{e}}=5.69 \times 10^{12} / \mathrm{cm}^{3}$

Fig. 31 discharge condition: $T_{e}=23 \mathrm{eV}, \mathrm{n}_{e}=2.30 \times 10^{12} / \mathrm{cm}^{3}$

The following figures are for $\mathrm{C}_{2} \mathrm{H}_{4}$ and the individual traces are:

a) $\mathrm{Cl}\left(\right.$ fig.9h), b) ClI (fig.9g), c) $\mathrm{H}^{\circ}$ (fig.9g), d) $\mathrm{CH}_{2}$ (fig.9d), e) $\mathrm{C}_{2}\left(\lambda=5582 \AA\right.$ ), f) $\mathrm{C}_{2}$ (fig.9c), g) $\mathrm{CH}^{+}$(fig.9b), h) CH (fig.9a)

Fig. 32 discharge condition: $T_{e}=34 \mathrm{eV}, \mathrm{n}_{e}=1.62 \times 10^{12} / \mathrm{cm}^{3}$

Fig.33 discharge condition: $\mathrm{T}_{e}=14 \mathrm{eV}, \mathrm{n}_{e}=5.53 \times 10^{12} / \mathrm{cm}^{3}$

The following figures are for $\mathrm{CO}$ and the individual traces are:

a) $\mathrm{CI}(\mathrm{fig} .9 \mathrm{~h})$, b) OI $(\lambda=8446 \AA)$ c) $\mathrm{CII}(\mathrm{fig} .9 \mathrm{~g})$, d) $\mathrm{CO}(\mathrm{fig.9e})$, e) $\mathrm{CO}(\lambda=5602 \AA), f) \mathrm{CO}^{+}$ (fig.9f)

Fig.34 discharge condition: $T_{e}=9 \mathrm{eV}, \mathrm{n}_{\mathrm{e}}=2.99 \times 10^{12} / \mathrm{cm}^{3}$

Fig.35 discharge condition: $\mathrm{T}_{e}=19 \mathrm{eV}, \mathrm{n}_{\mathrm{e}}=3.03 \times 10^{12} / \mathrm{cm}^{3}$ 


\section{Identification Table for Molecular Bands}

$\mathrm{CO}^{+} \quad$ (1) Comet tail system, $\quad \mathrm{A}^{2} \Pi-\mathrm{X}^{2} \Sigma$

Two strong $R$ heads with corresponding $Q$ heads lying from 5 to 1.5 A to the red or $R$ heads

CO

(2) Angstrom system,

$\mathbf{B}^{1} \mathbf{\Sigma}-\mathbf{A}^{1} \boldsymbol{\Pi}$

$\mathrm{C}_{2}$

(3) Swan system,

$$
A^{3} \Pi_{g}-X^{13} \Pi_{u}
$$

$\mathrm{C}_{2}$

(4) Deslandres-d'Azambuia system,

$c^{1} \Pi_{\mathrm{g}}-b^{1} \Pi_{\mathrm{u}}$

CH

(5) 4300 \& system,

$A^{2} \Delta-X^{2} I I$

$Q$ head of the $(0,0)$ band is at $4314.2 \AA$. A line -like feature at $4324 A$ is the piled up $Q$ branch of the $(2,2)$.

CH

(6) 3900 A system,

$B^{2} \Sigma-X^{2} \Pi$

$\mathrm{CH}_{2}$

(7) Methylene radical,

$b^{1} B_{1}-a^{1} A_{1}$

$\mathrm{CO}$

(8) The Triplet Bands,

$d^{3} \Delta-a^{3} \Pi$

CO

(9) Third Positive Bands,

$b^{3} \Sigma-a^{3} \Pi$

$\mathrm{CO}^{+} \quad$ (10)Baldet-Johnson system,

$B^{2} \Sigma-A^{2} \Pi$

CO (11)Asundi bands,

$a^{3} \Sigma-a^{3} \Pi$

$\mathrm{CO}$

(12)5B bands.

$b^{3} \Sigma-a^{3} \Pi$

$\mathrm{CO}$

(13)Herman bands.

$e^{3} \Sigma^{-}-a^{3} \Pi$

$\mathrm{CO}_{2}^{+}$

(14)Fox. Duffendack and Barker's

$A^{2} \Pi-X^{2} \Pi$ System

$\mathrm{CO}_{2}^{+}$

(15)Bands $\lambda \lambda 2883$ and $\lambda \lambda 2896$

$A^{2} \Sigma^{+}-X^{2} \Pi$

$\mathrm{CO}_{2}$

(16)CO flame bands

${ }^{1} B_{2}-X^{1} \Sigma^{+}$

$\mathrm{CH}^{+}$

(17)Douglas-Herzberg system

$A^{1} \Pi-X^{1} \Sigma$ 


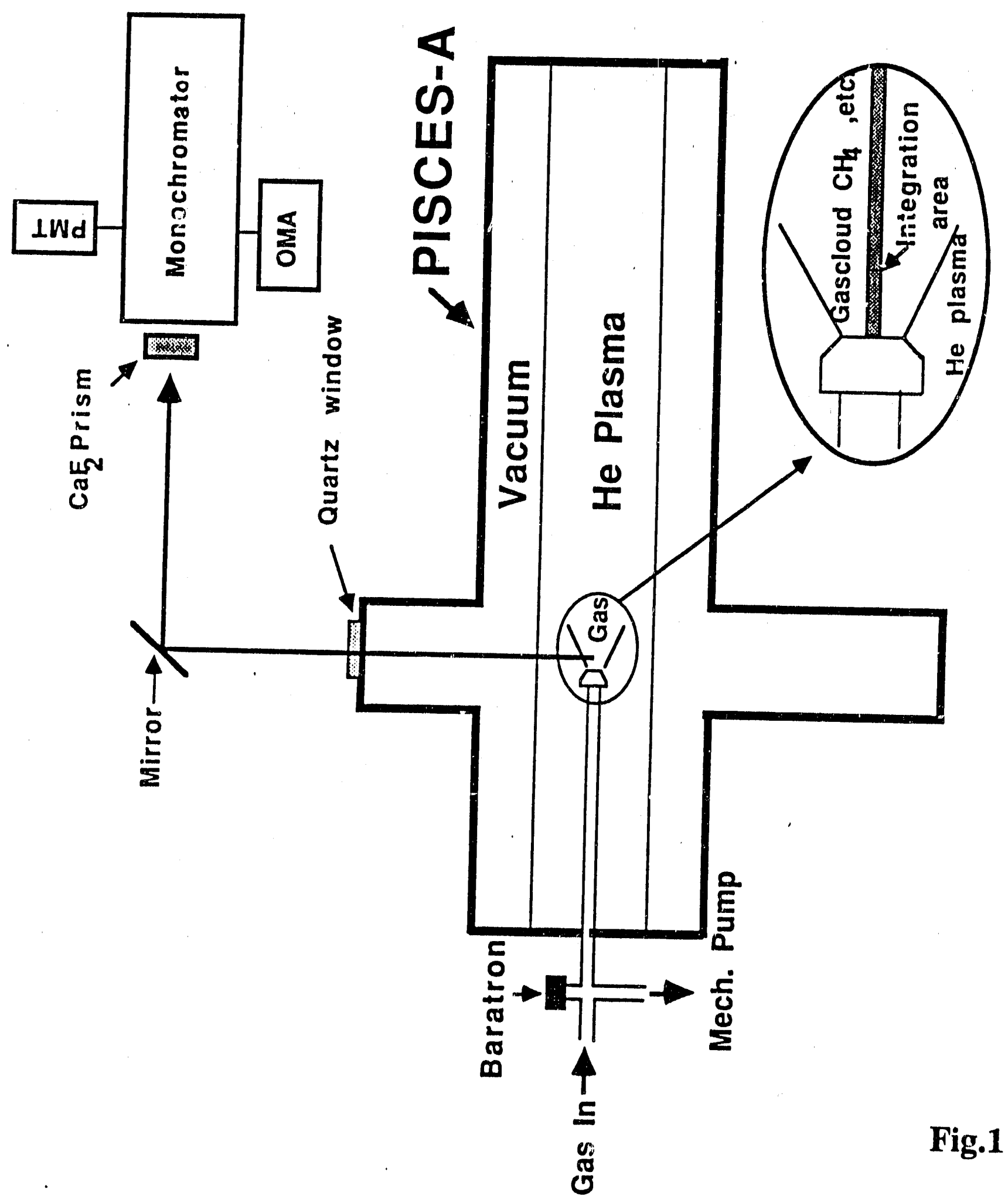



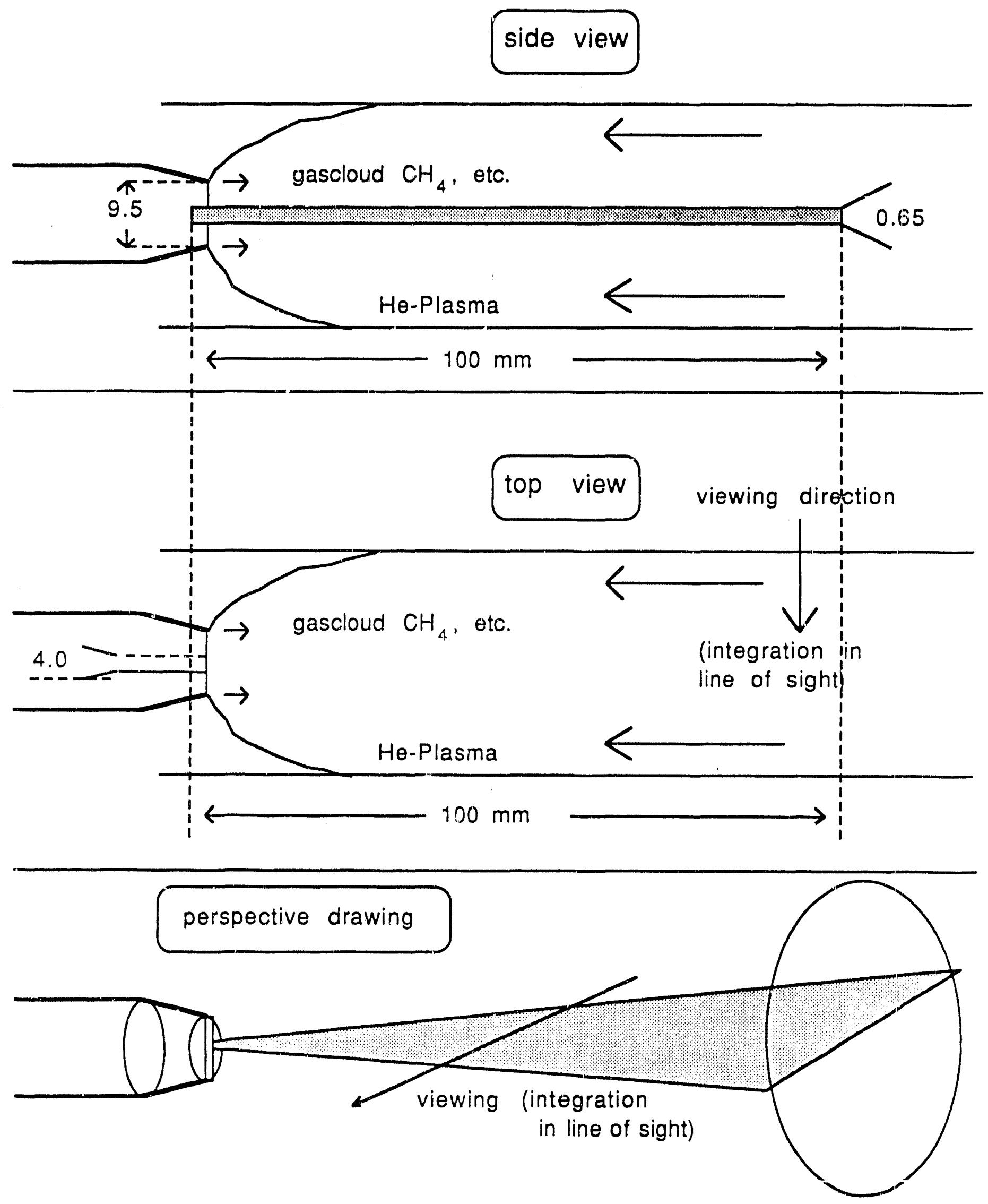

Fig.2 

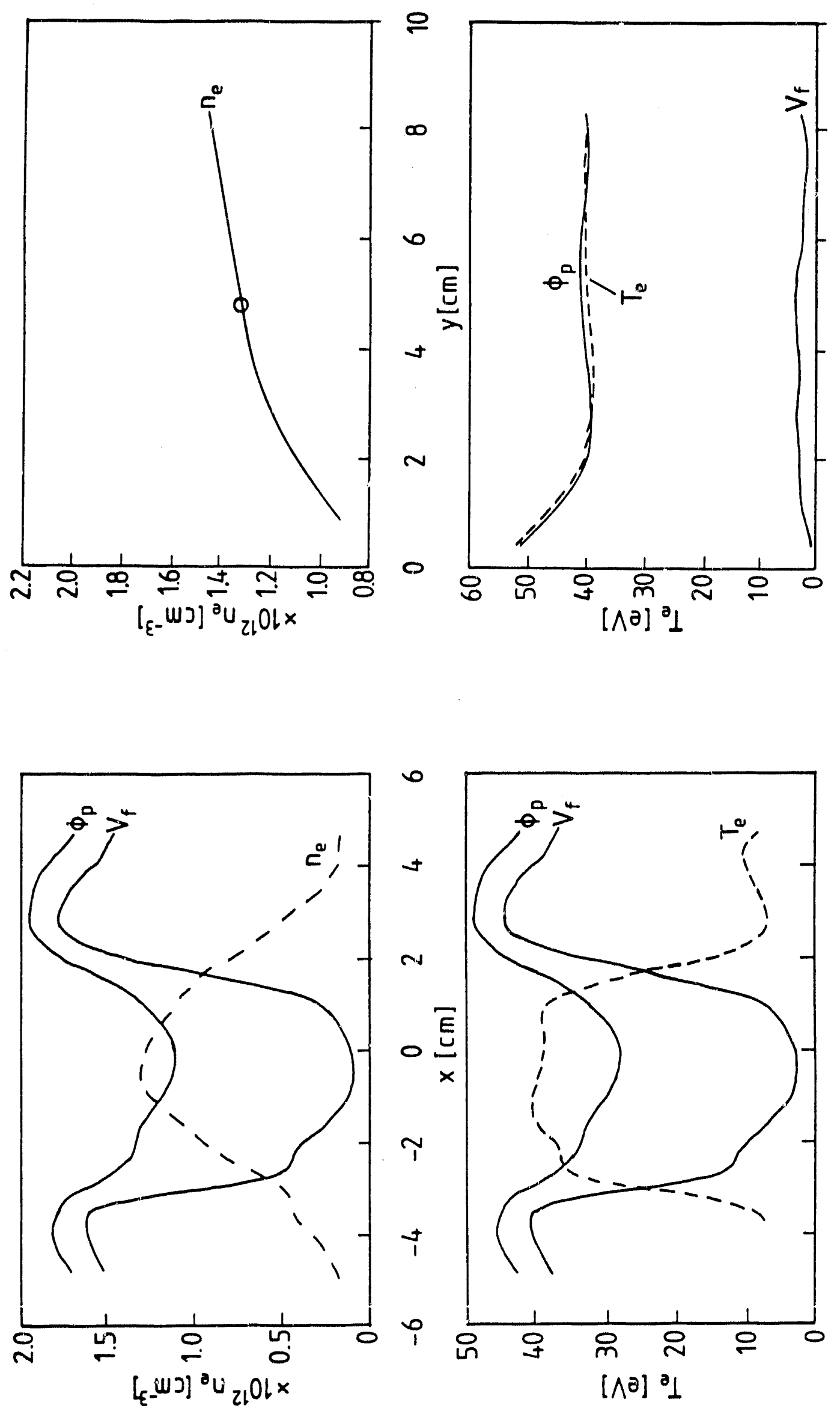

Fig.3a 

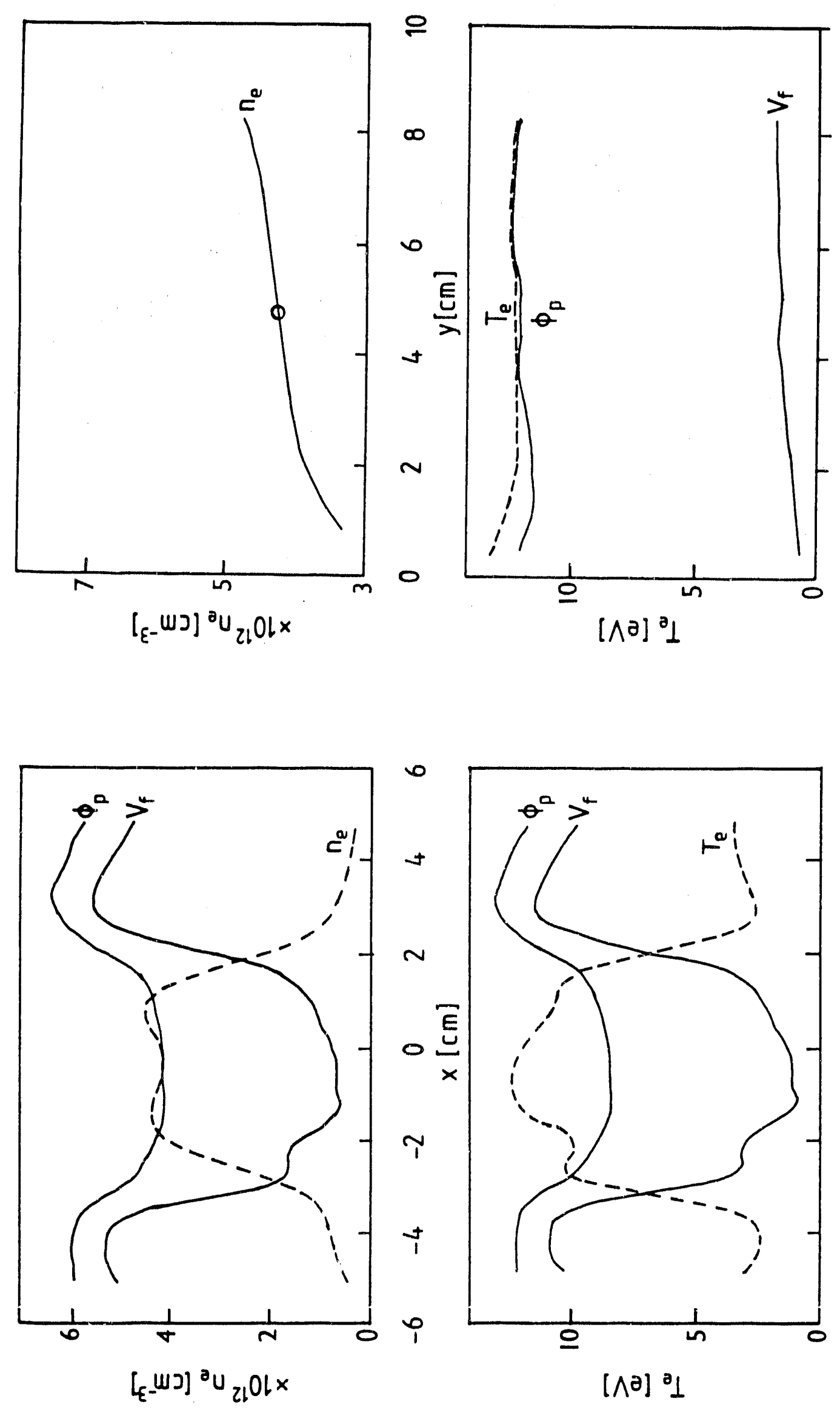

Fig.3b 


$$
\|_{1}
$$




$$
\|
$$



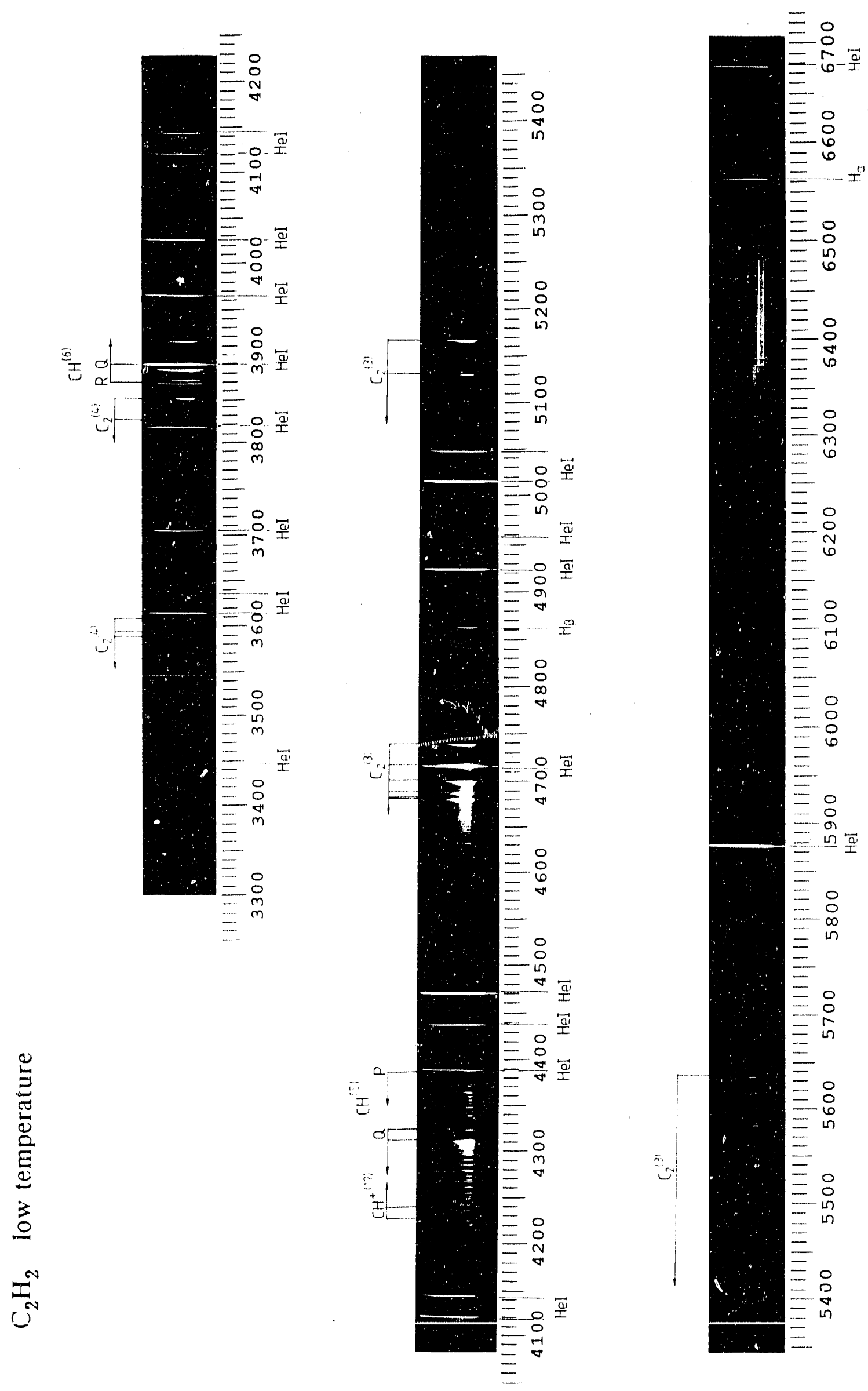

Fig. 5a 


$$
\|
$$




$$
\|_{1}
$$



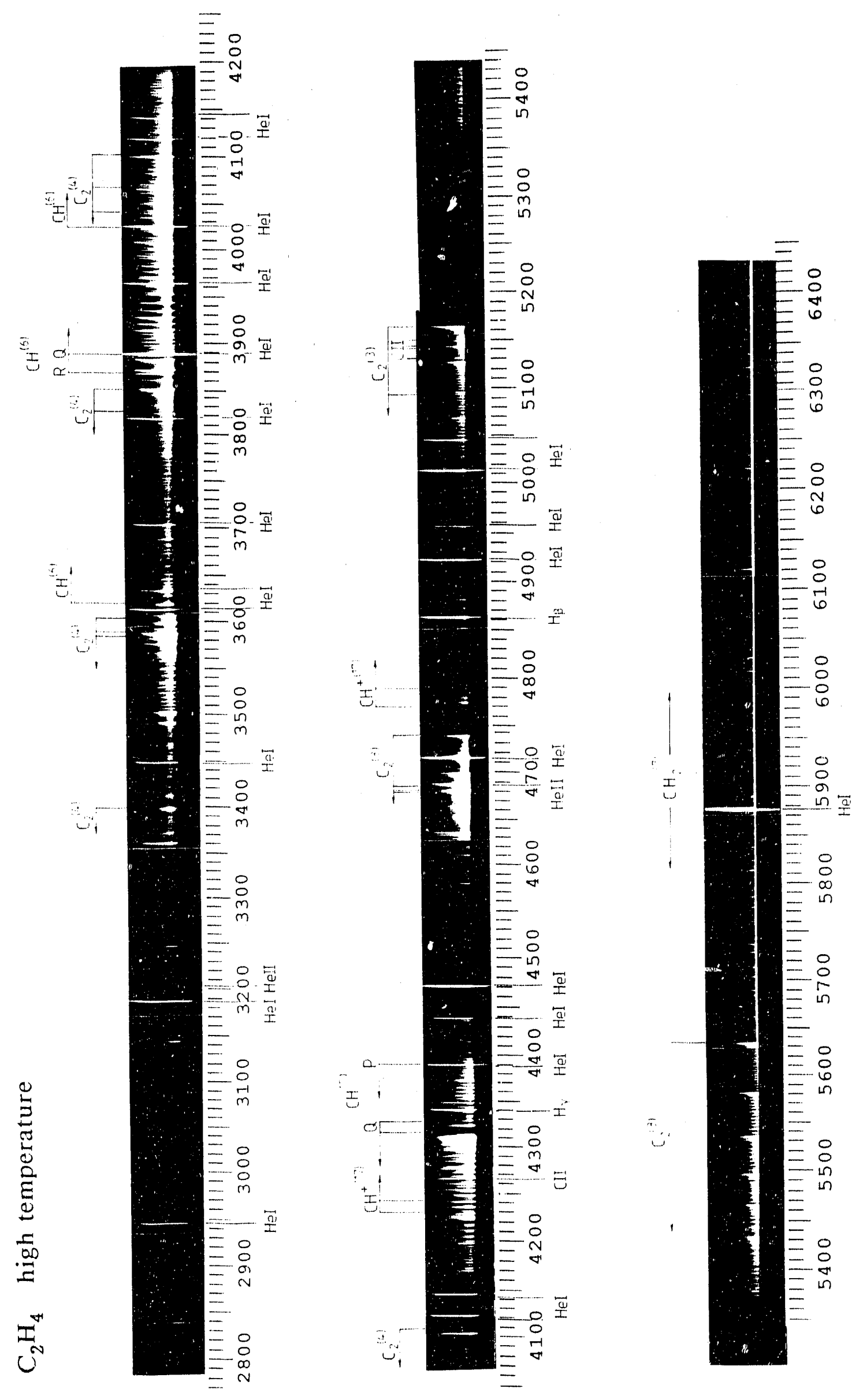

Fig. 6b 


$$
\|
$$



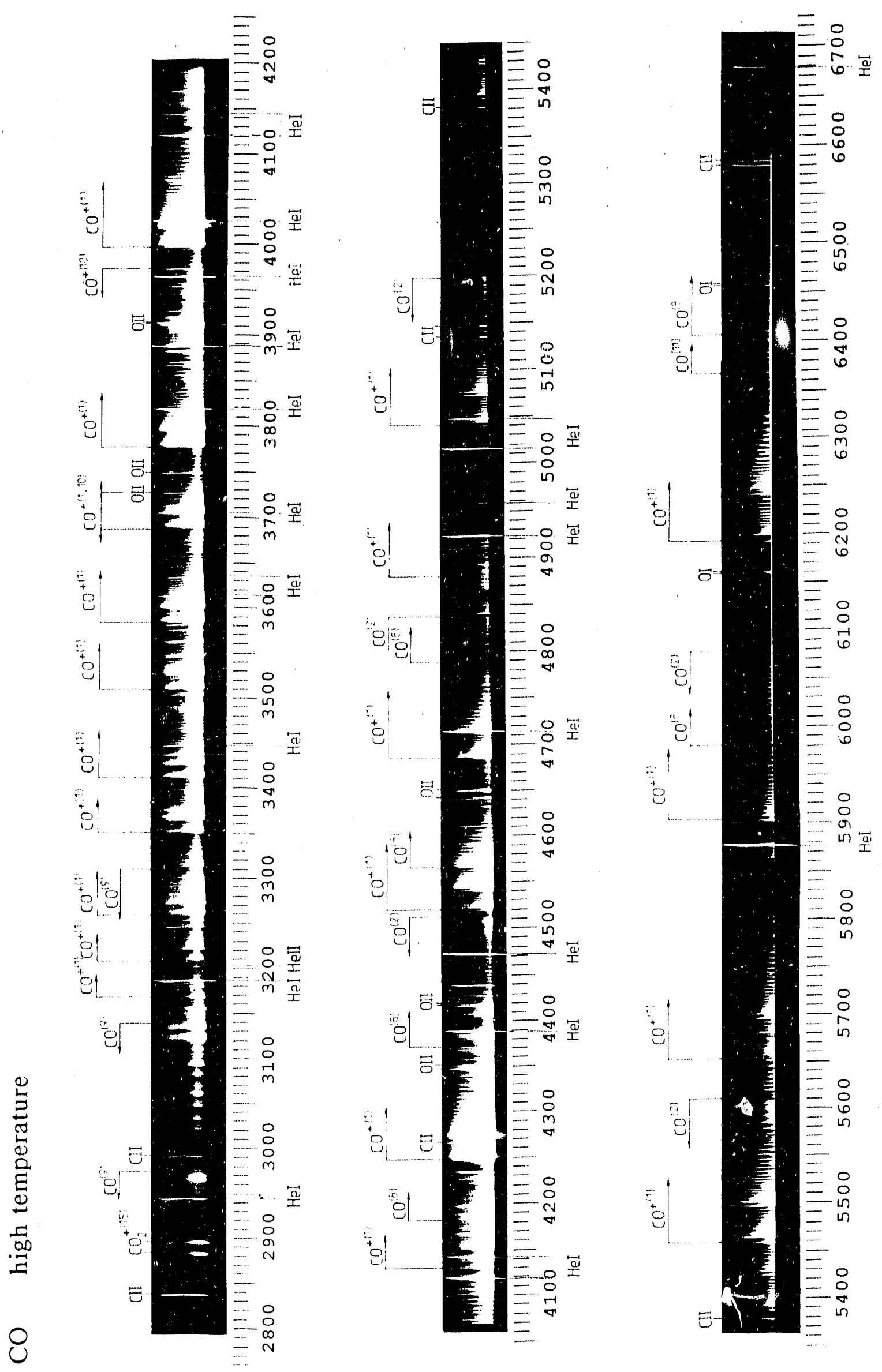

Fig. 7b 


$$
\|
$$




$$
||
$$



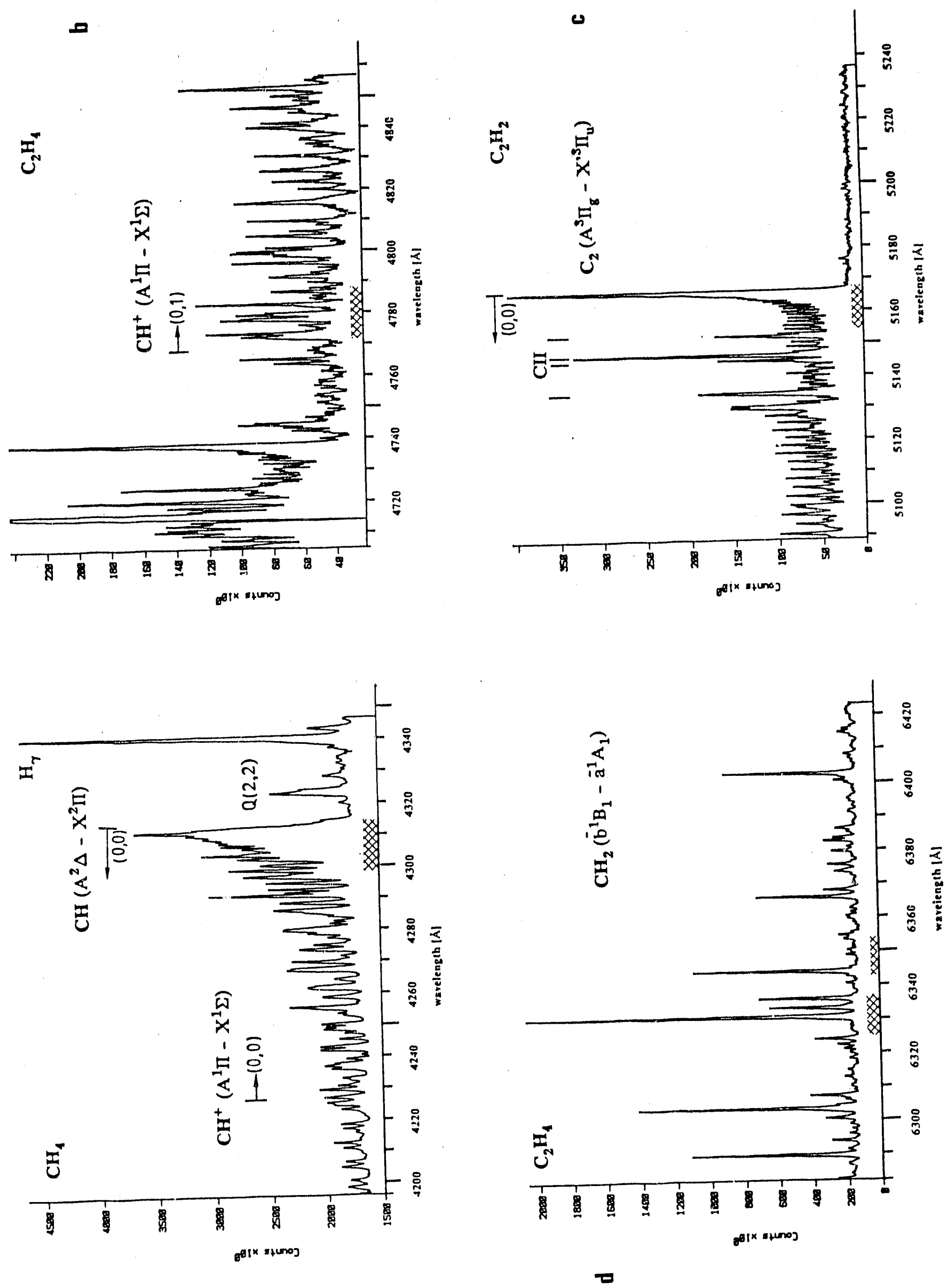

(10

Fig.9 

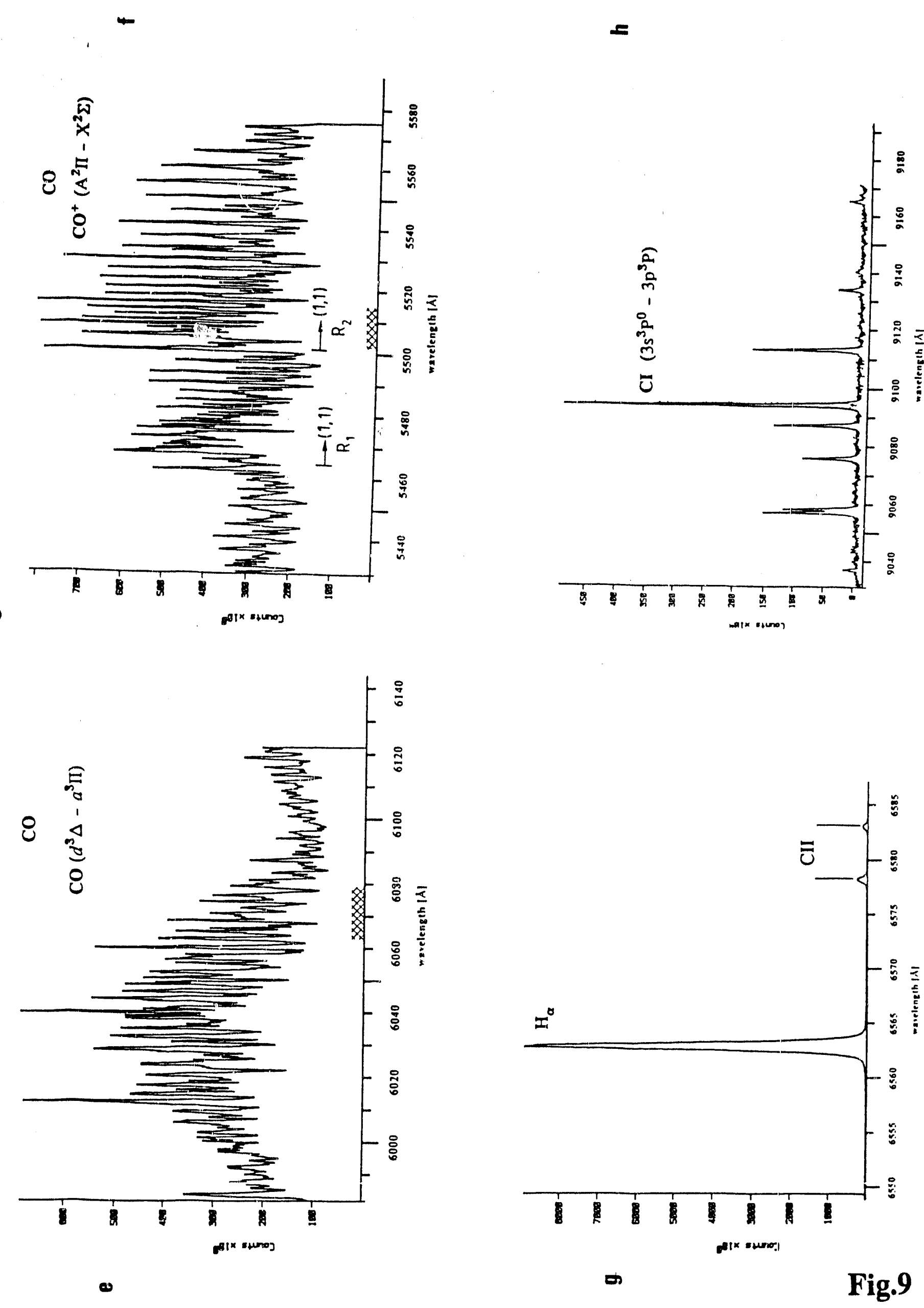

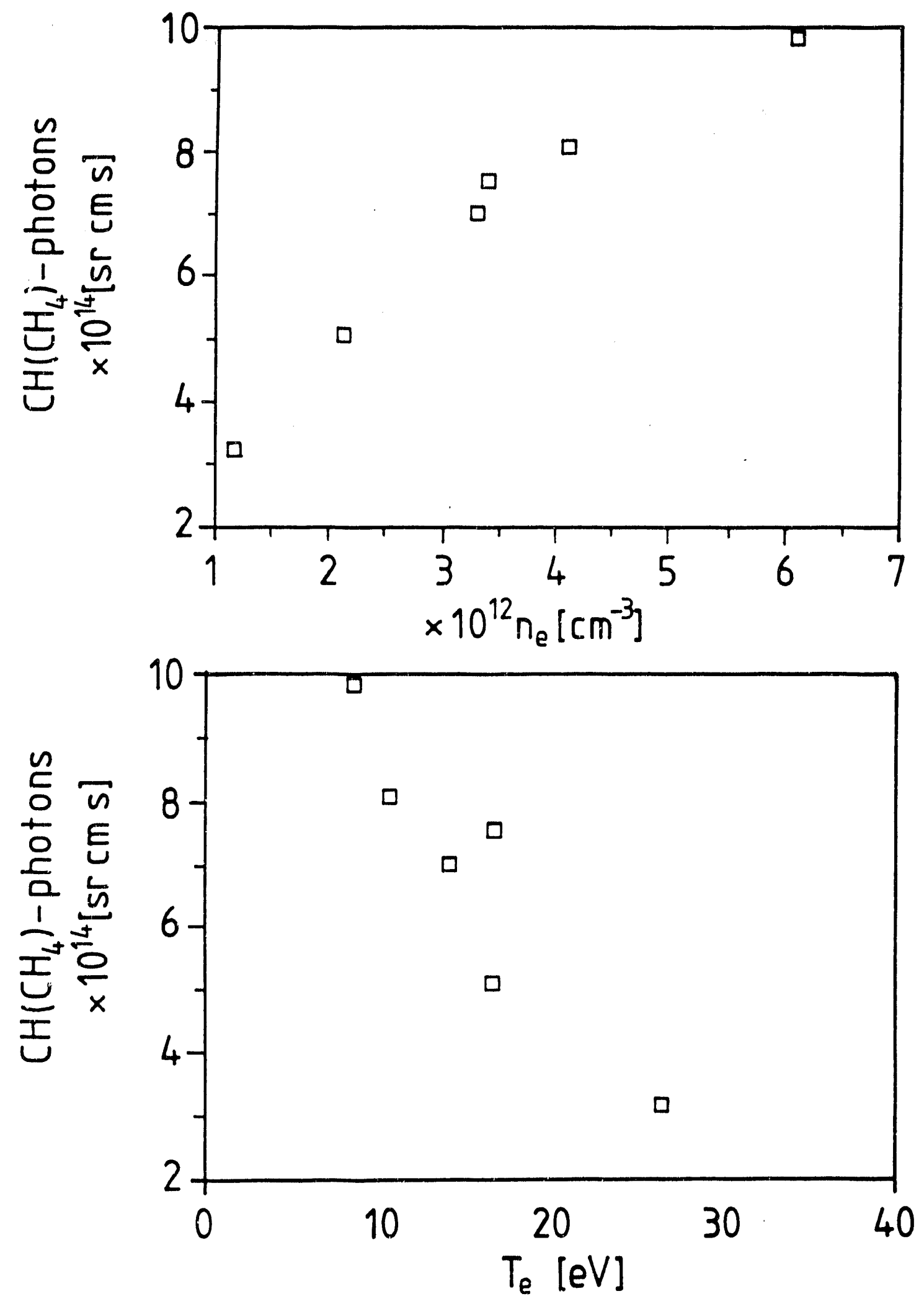

Fig.10 

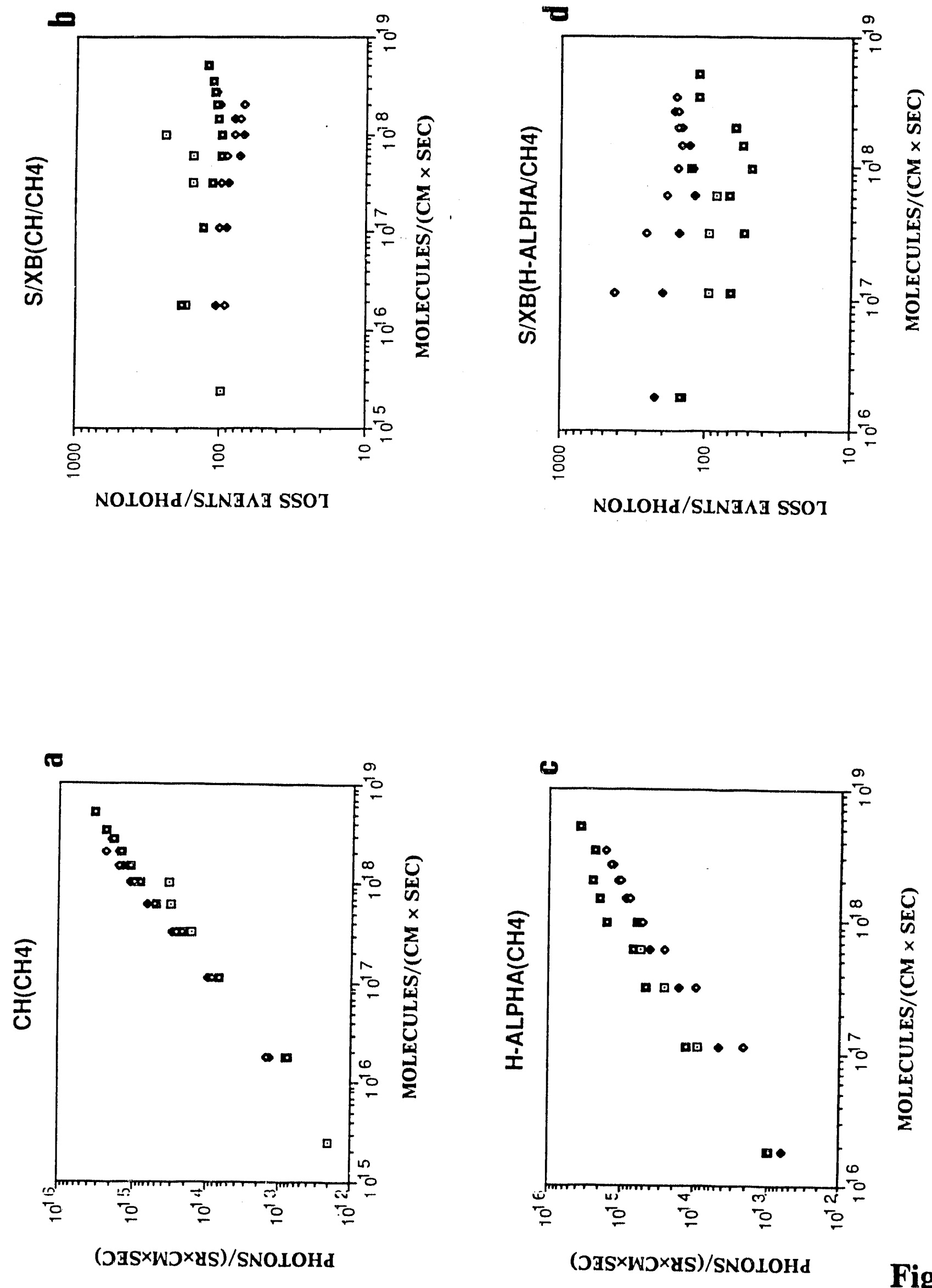

Fig.11 

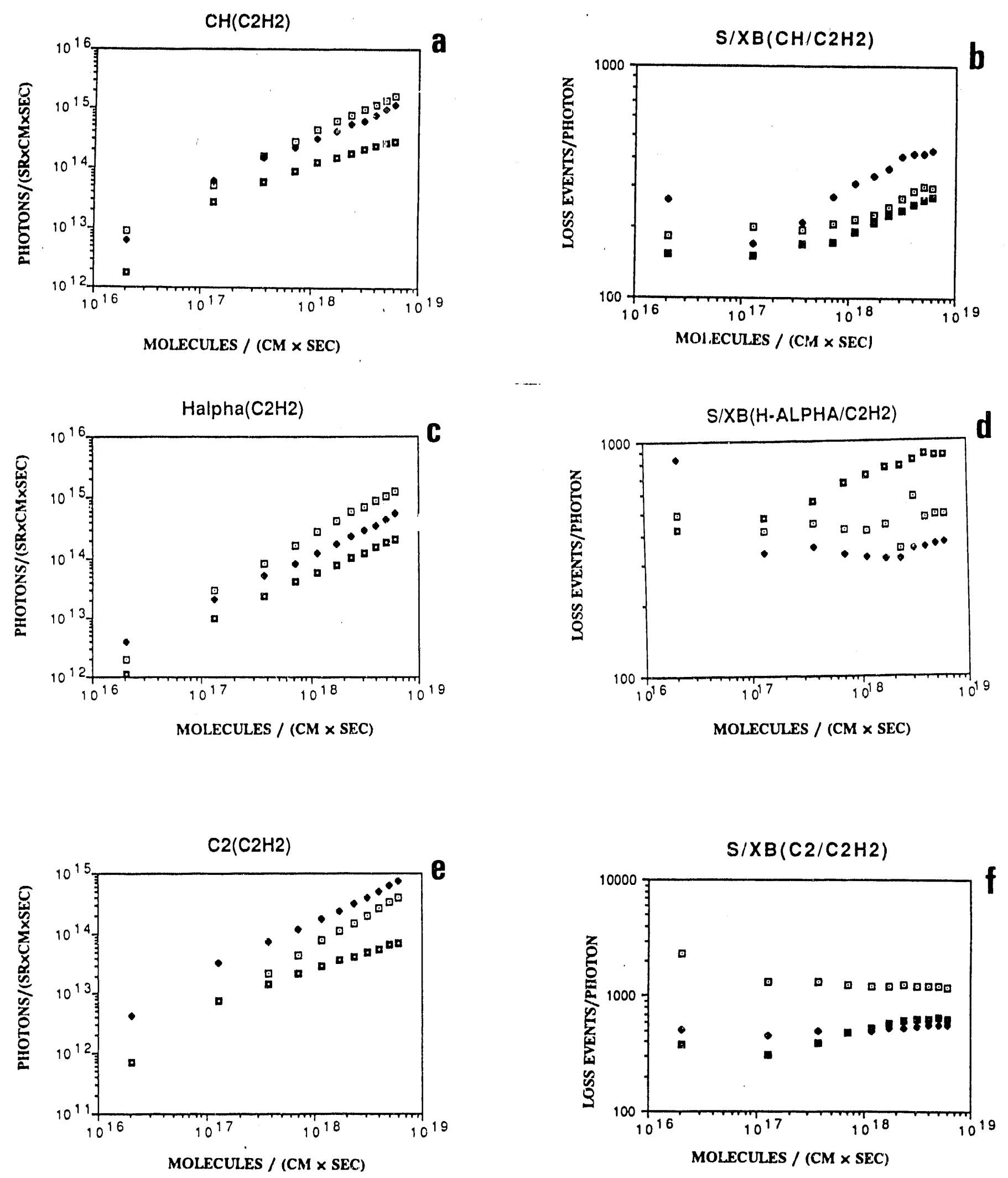

Fig.12 

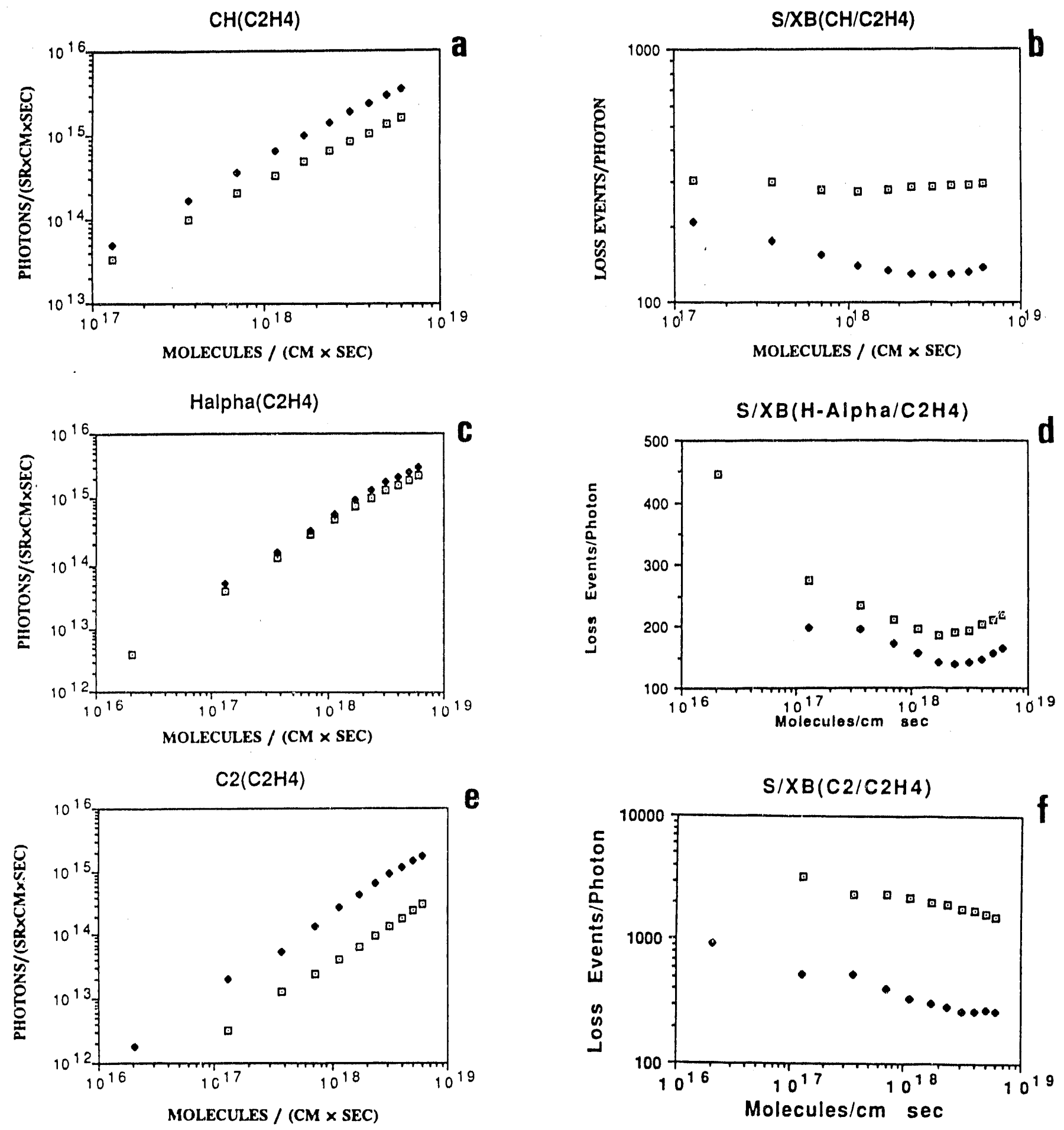

Fig.13 

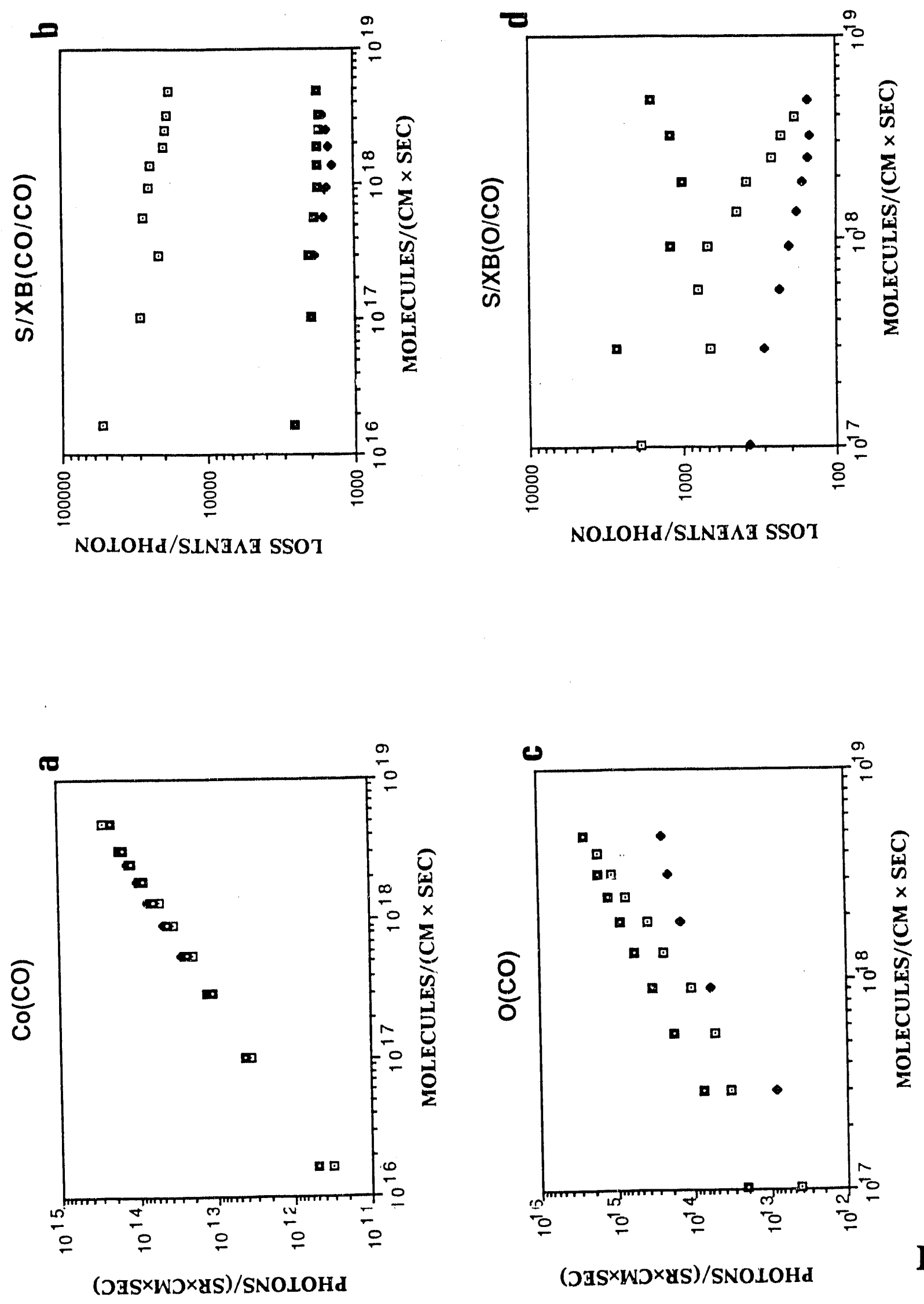

Fig.14 

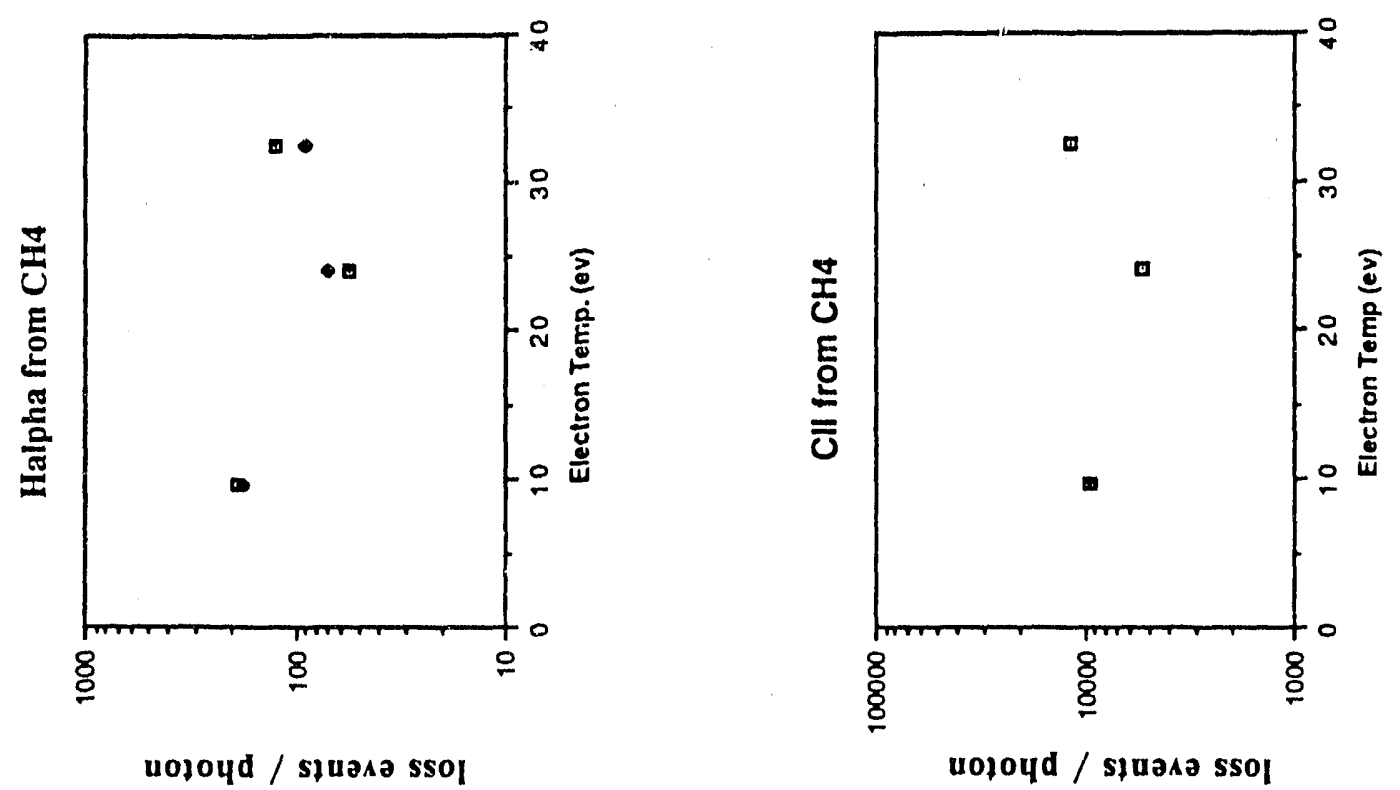

$\frac{\pi}{0}$
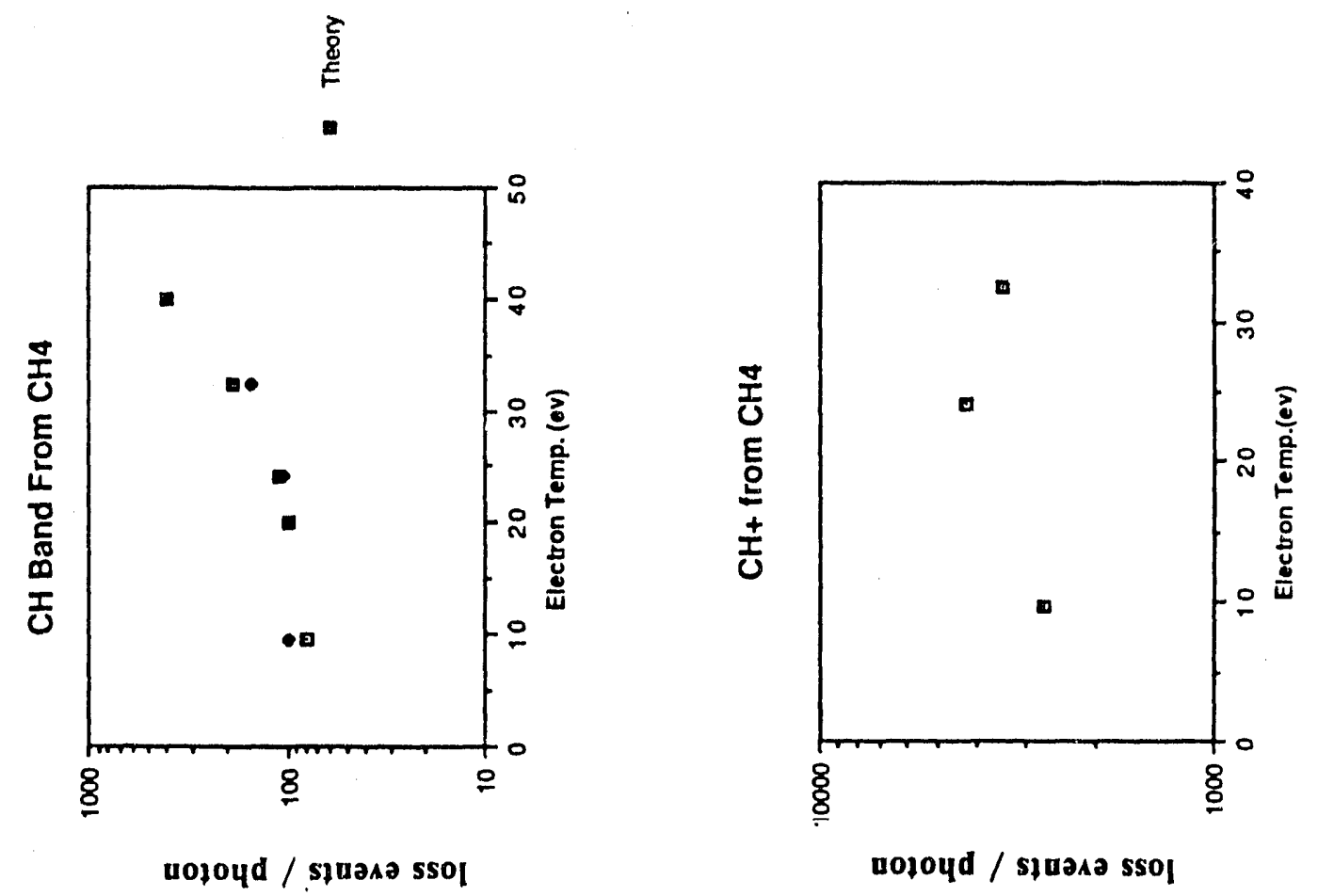

Fig.15 

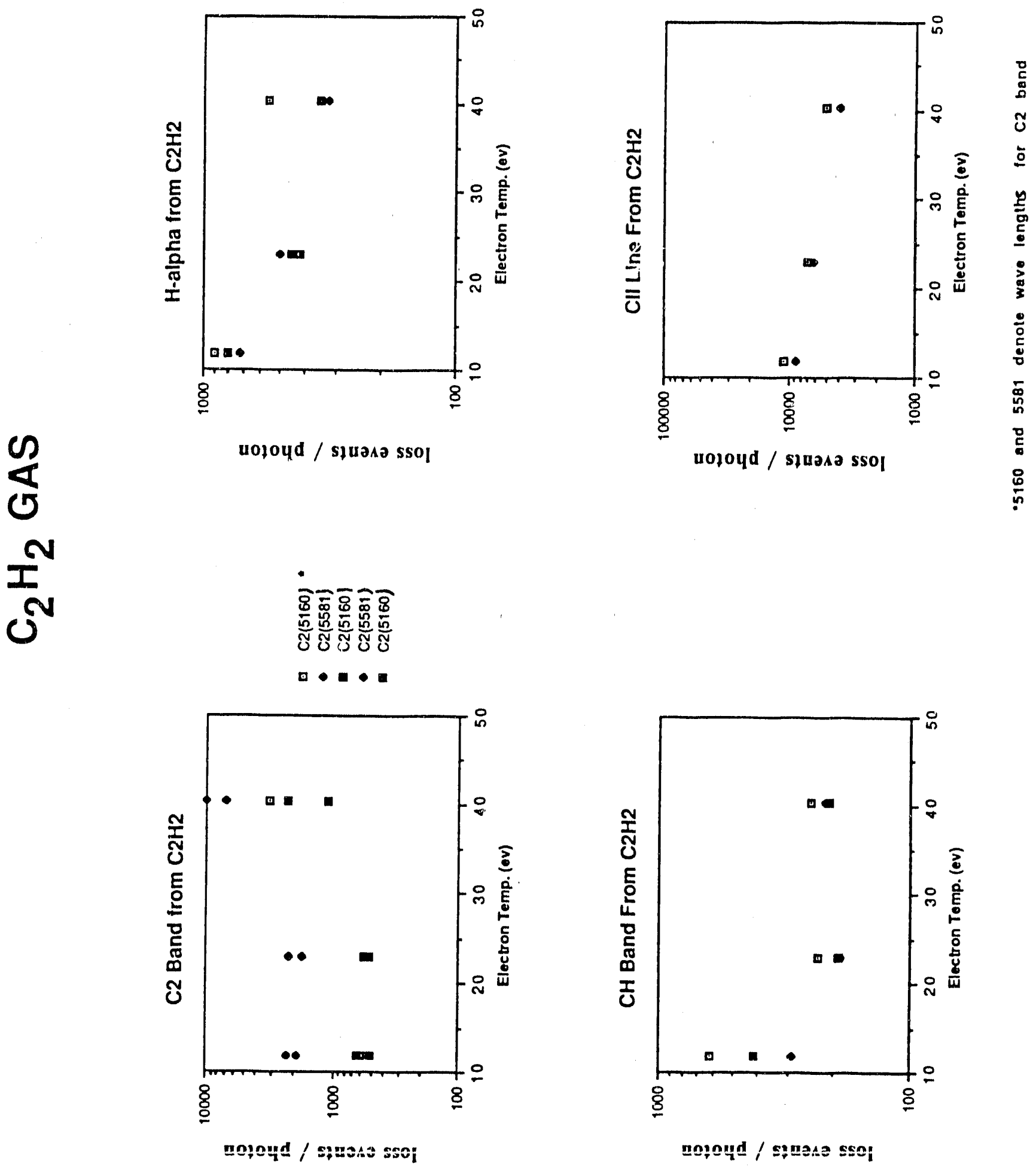

Fig.16 


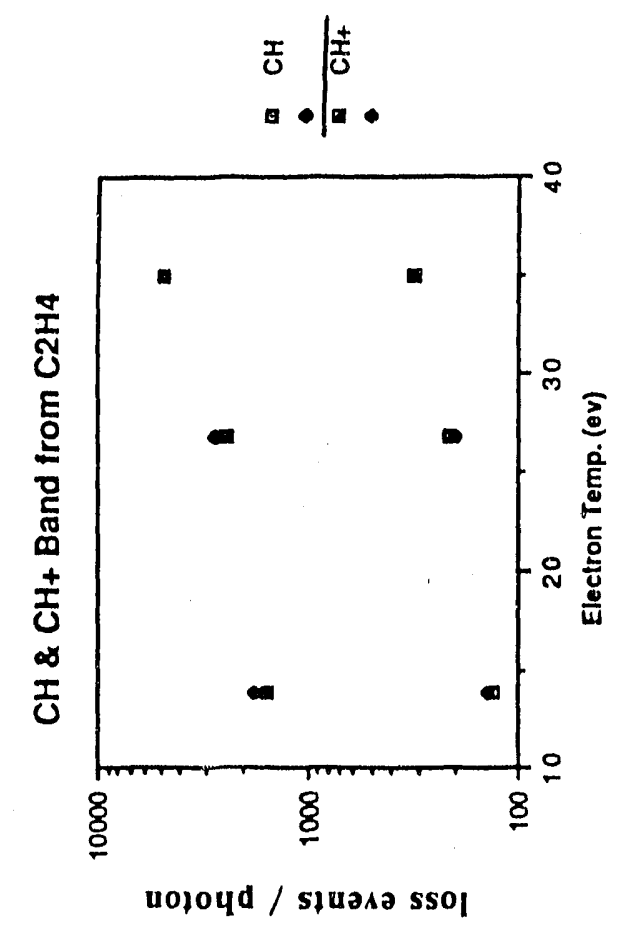

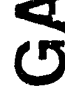

$\frac{T}{S^{N}}$
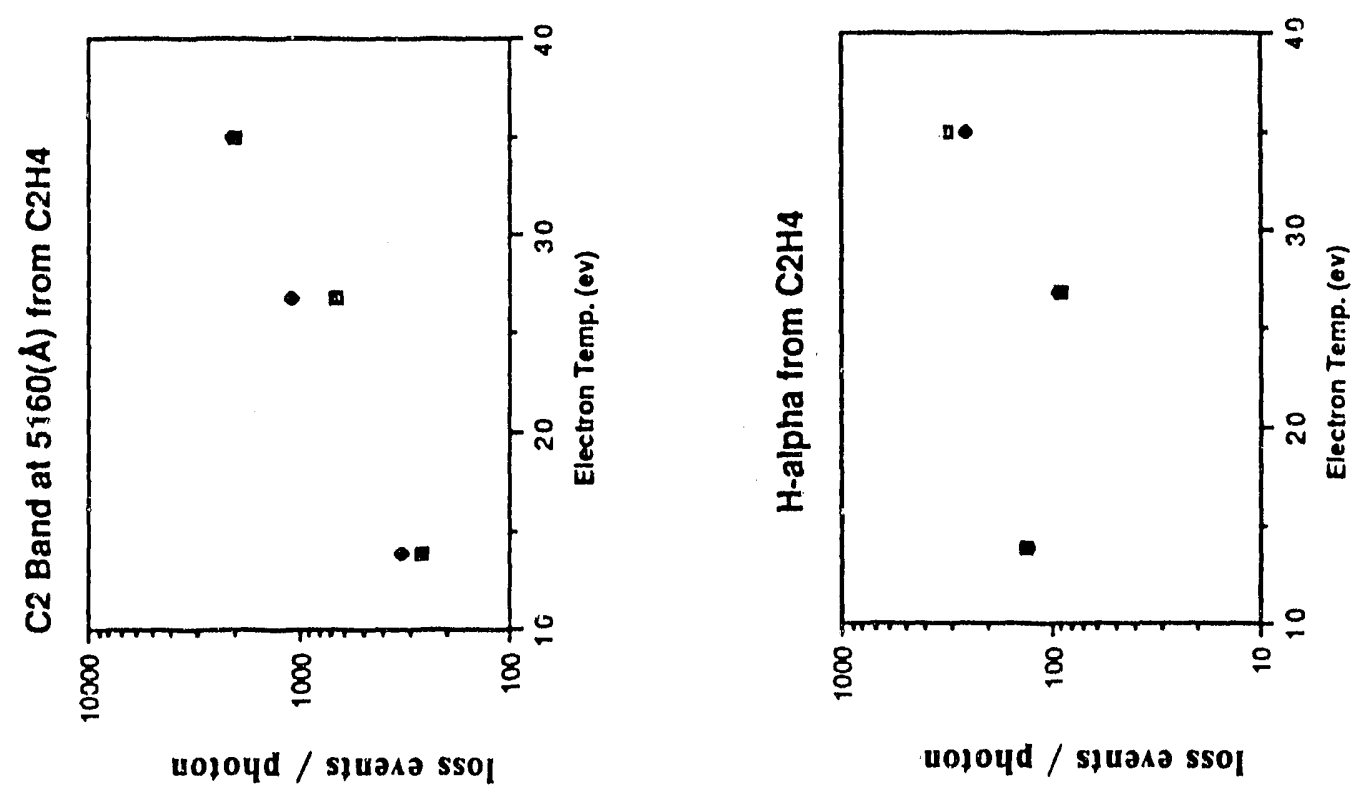

Fig.17 


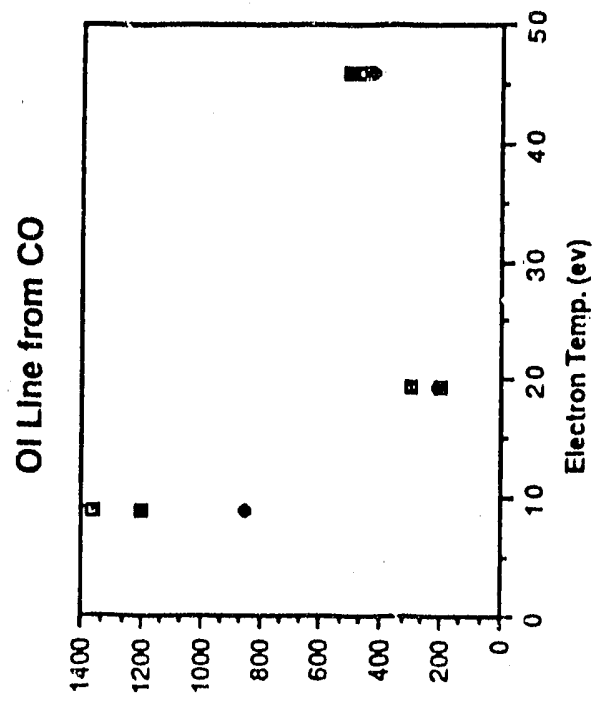

uojoyd / słuane ssol

a

$\tilde{U}$

0

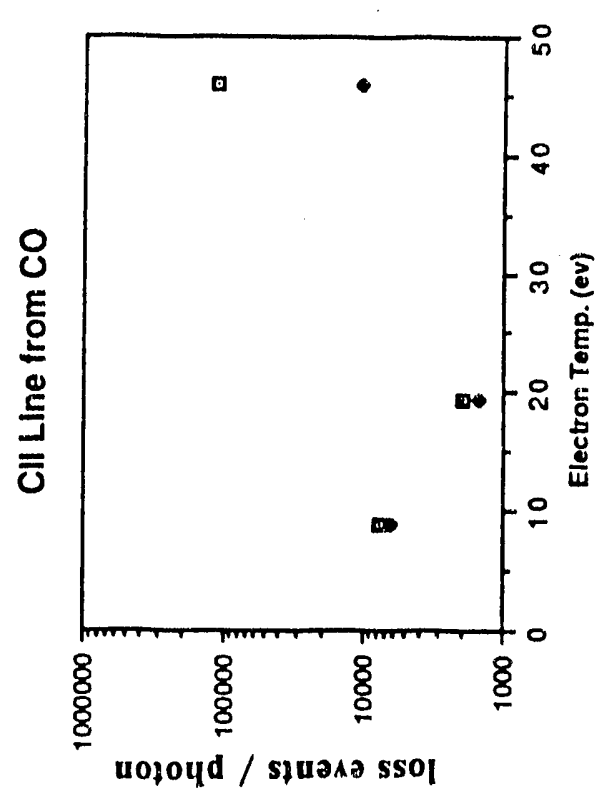

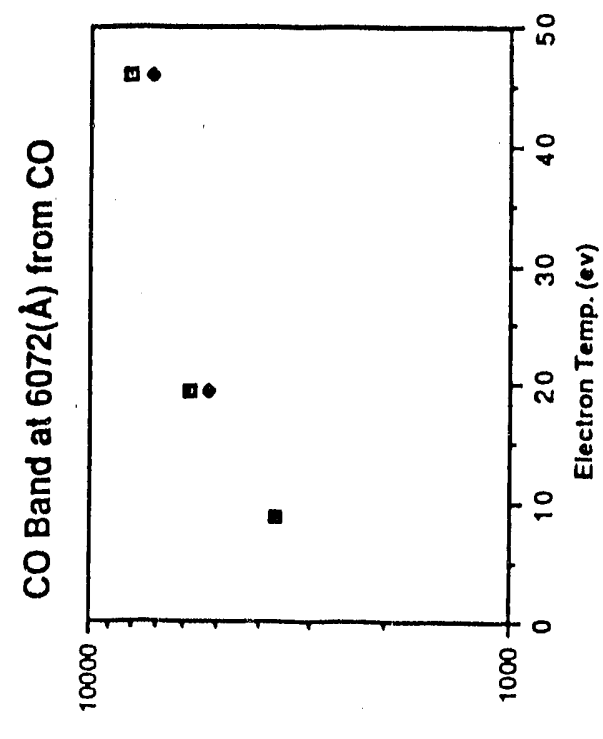

wopoyd / spuana ssol

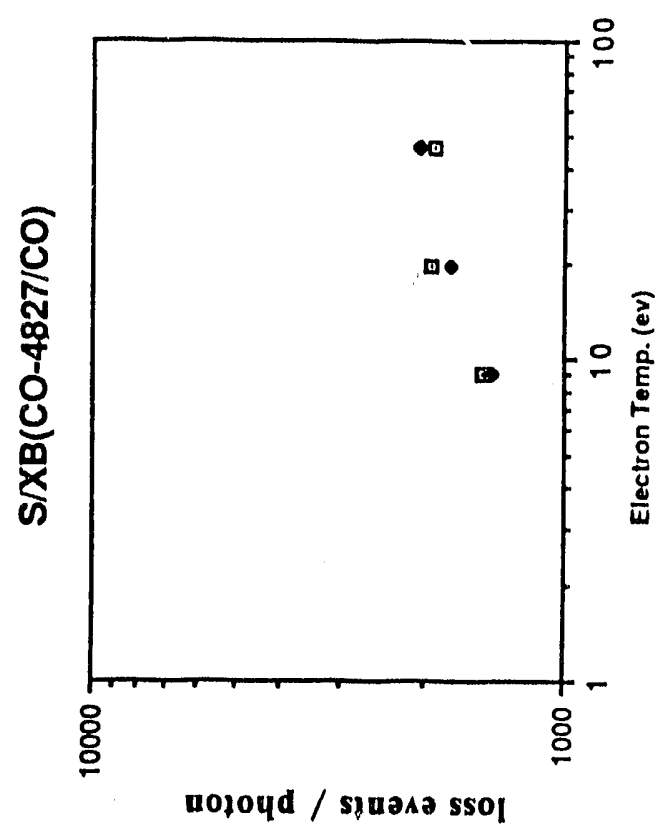

Fig.18 
$\mathrm{C} 2 / \mathrm{CH}(\mathrm{C} 2 \mathrm{H} 2)$

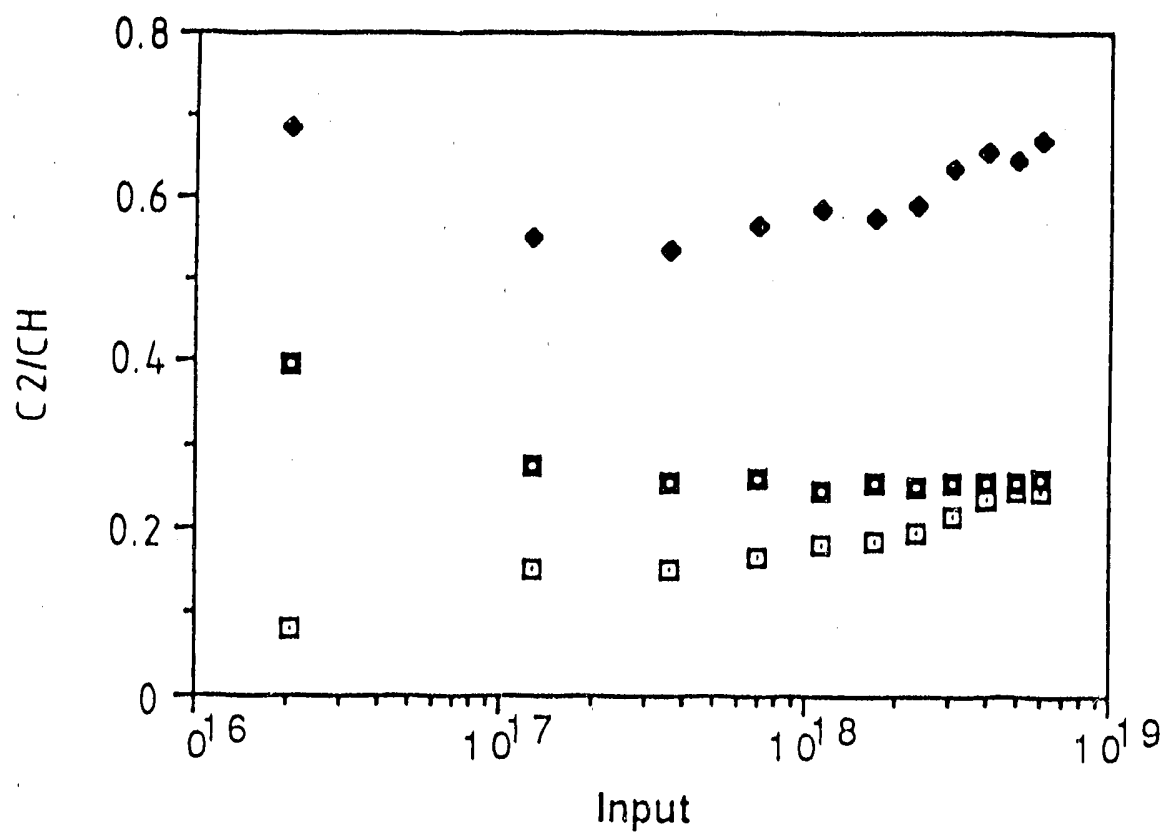

$\mathrm{C} 2 / \mathrm{CH}(\mathrm{C} 2 \mathrm{H} 4)$

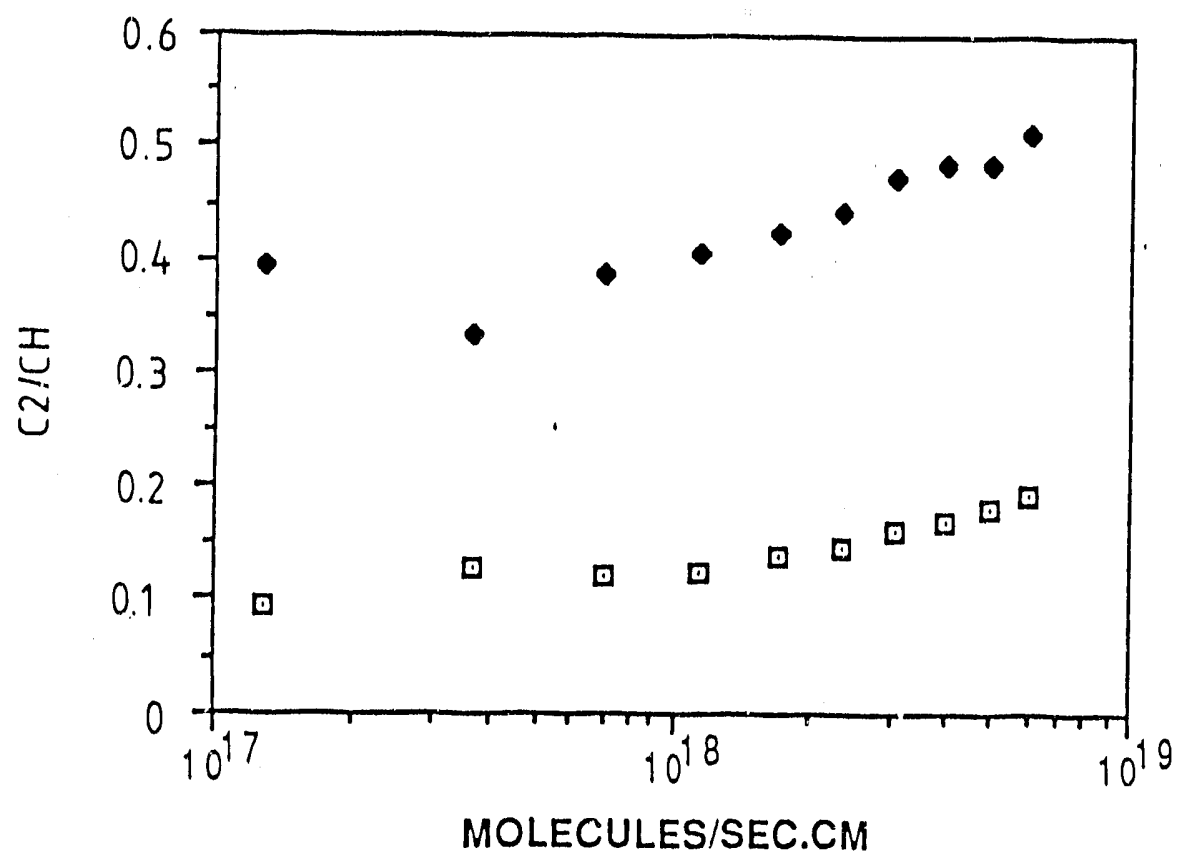

Fig.19 

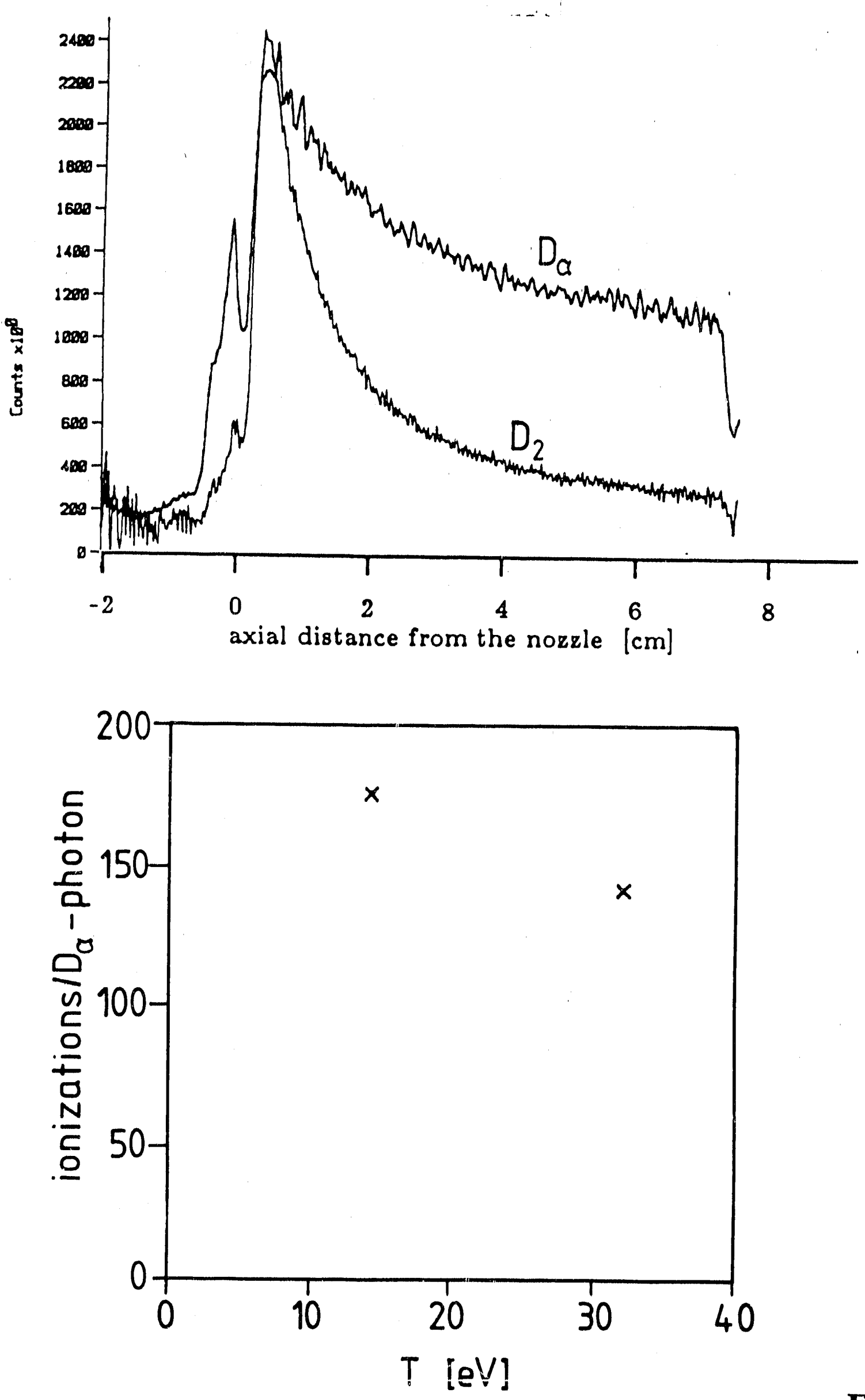

Fig.20 
$\mathrm{CH}_{4}$
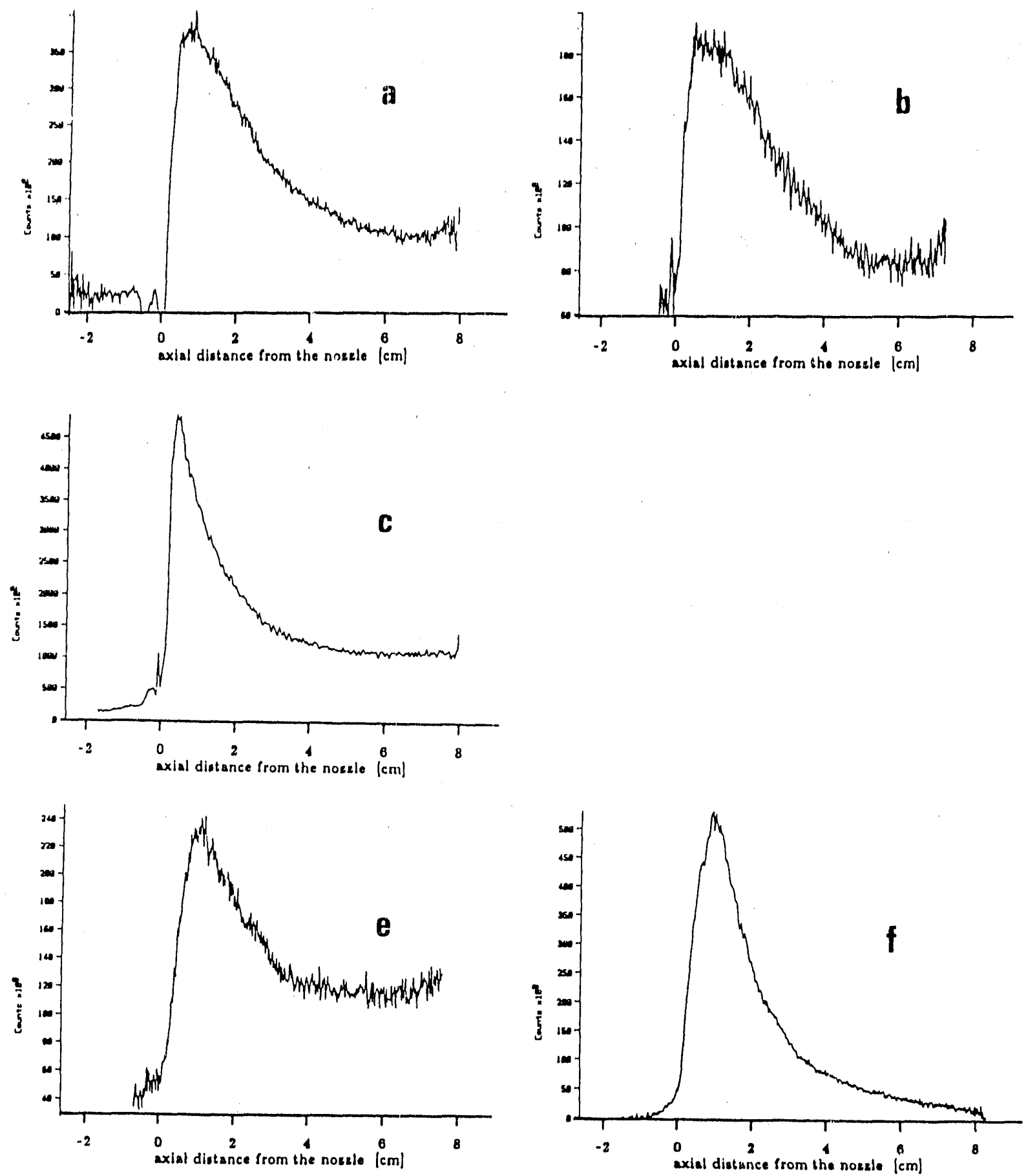

Fig. 21 
$\mathrm{CH}_{4}$
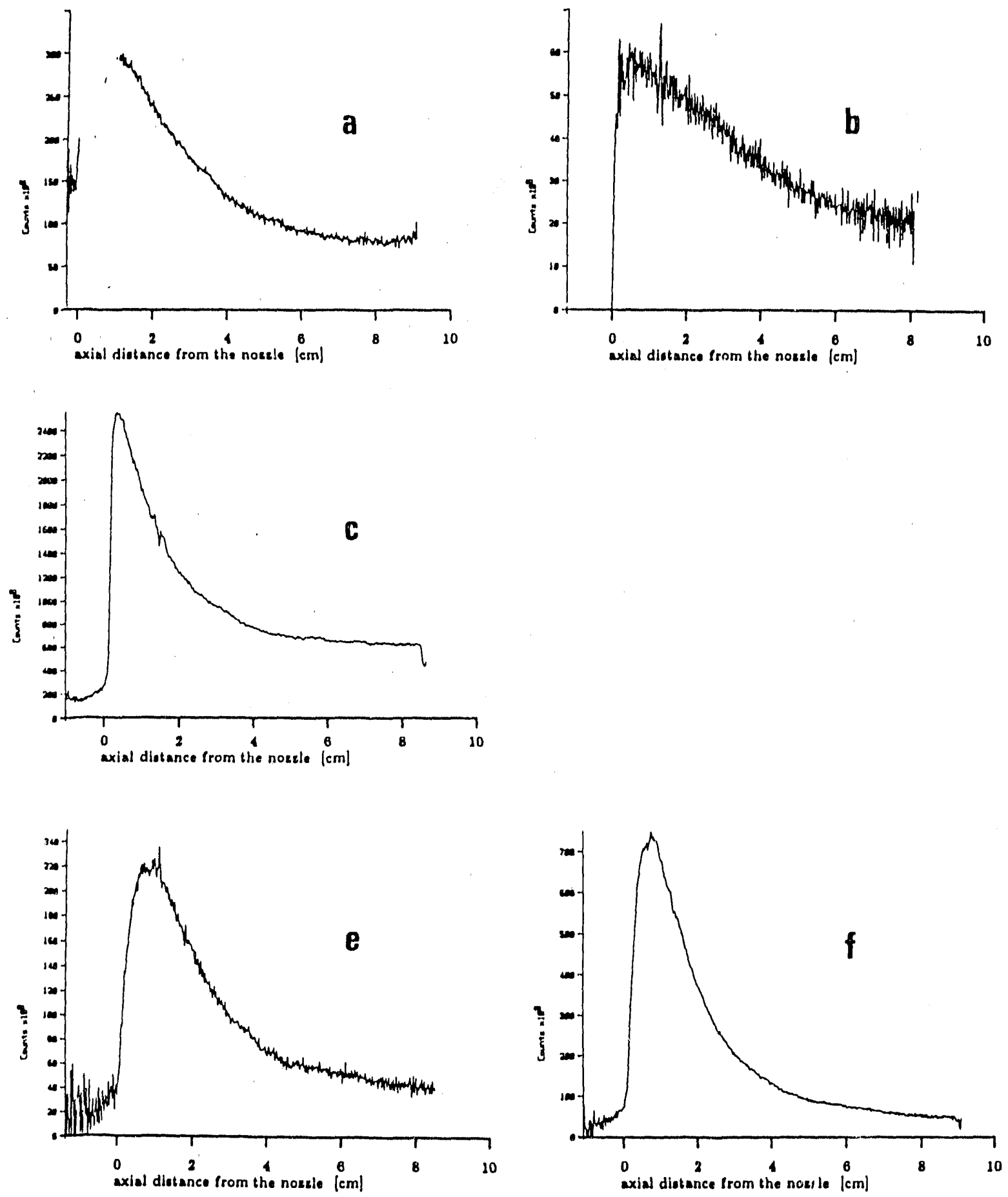

Fig. 22 


\section{$\mathrm{CH}_{4}$}
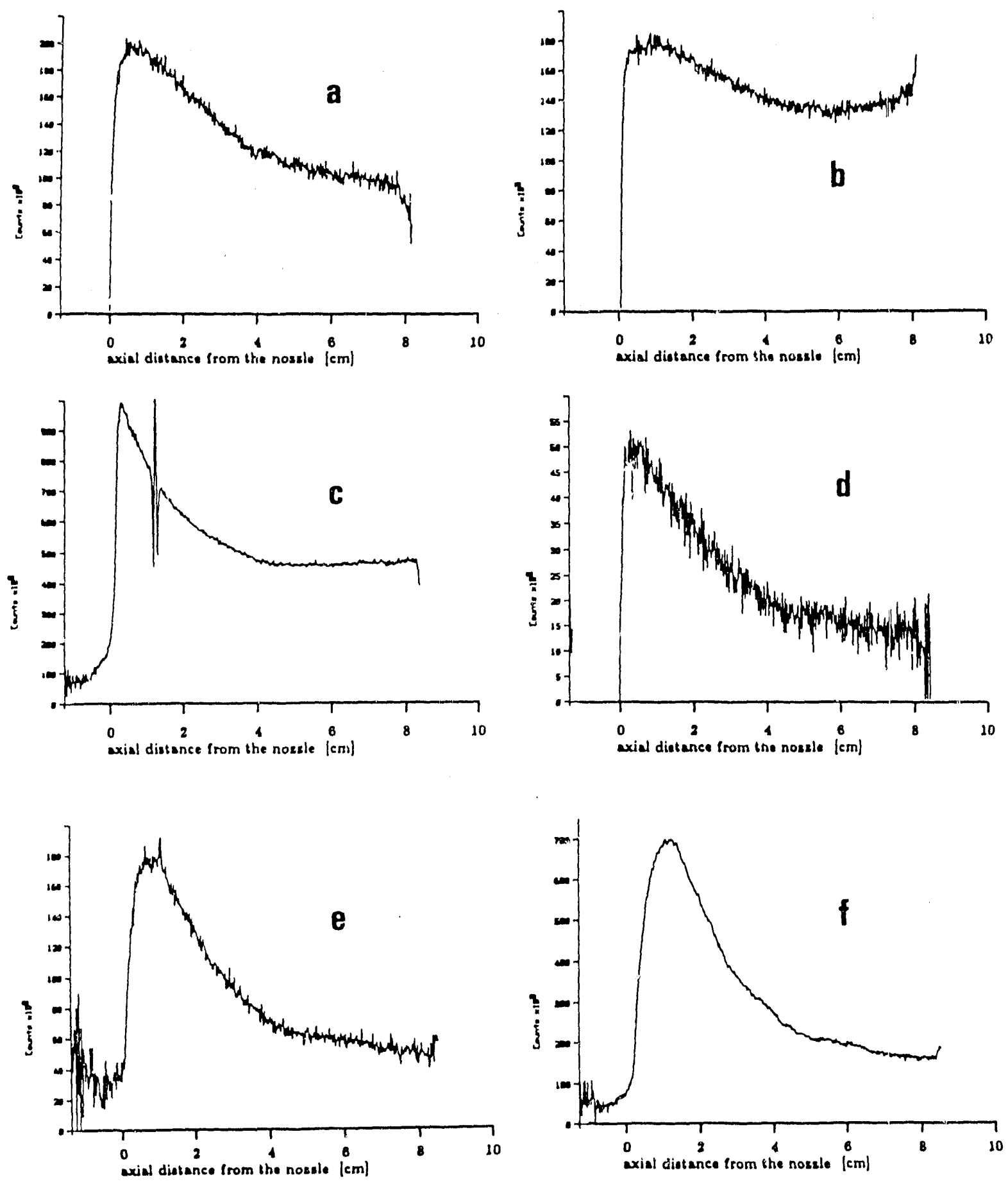

Fig. 23

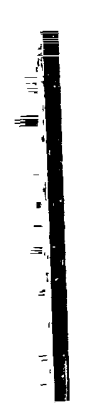




\section{$\mathrm{CH}_{4}$}
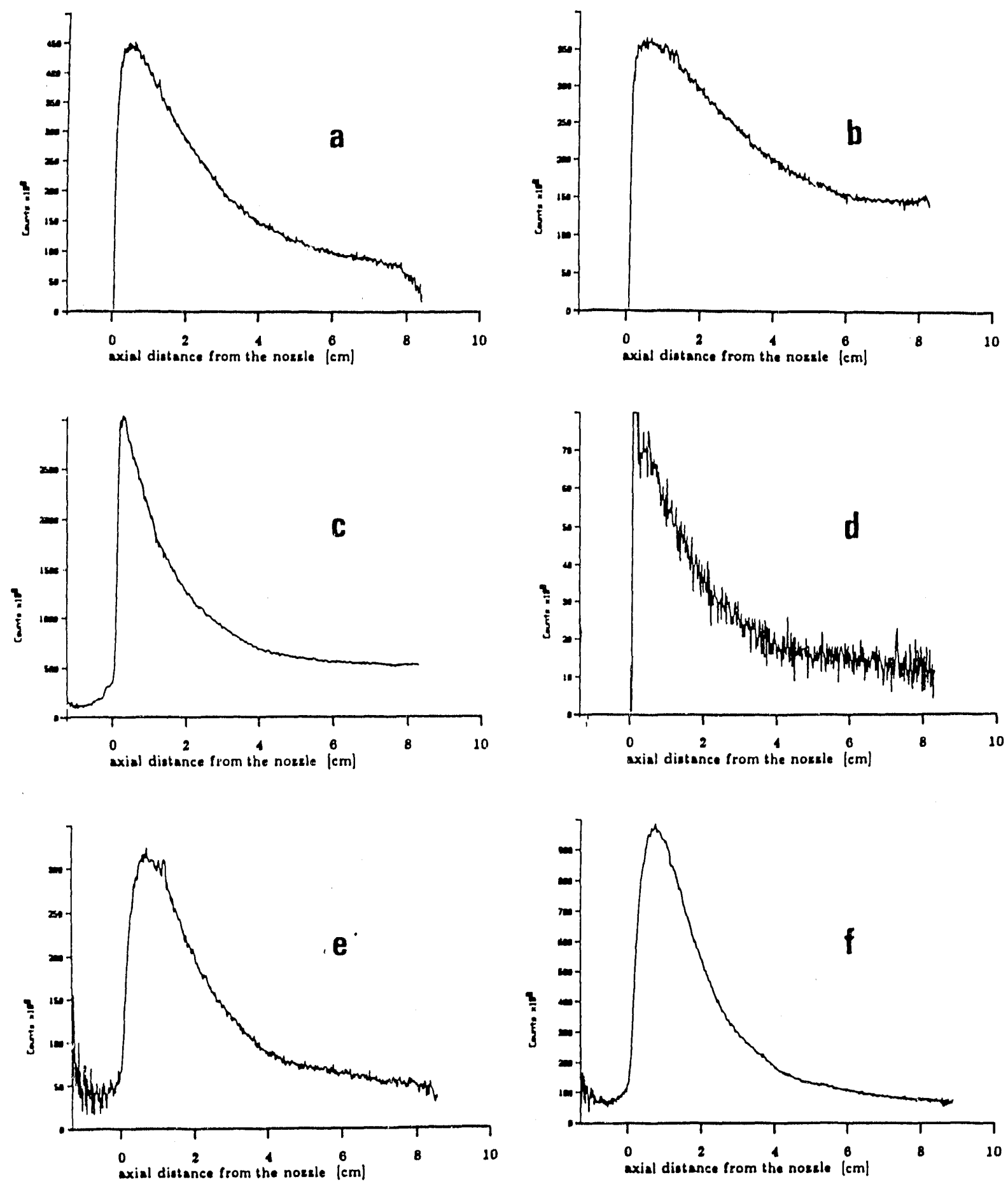

Fig. 24 


\section{$\mathrm{CH}_{\mathbf{4}}$}
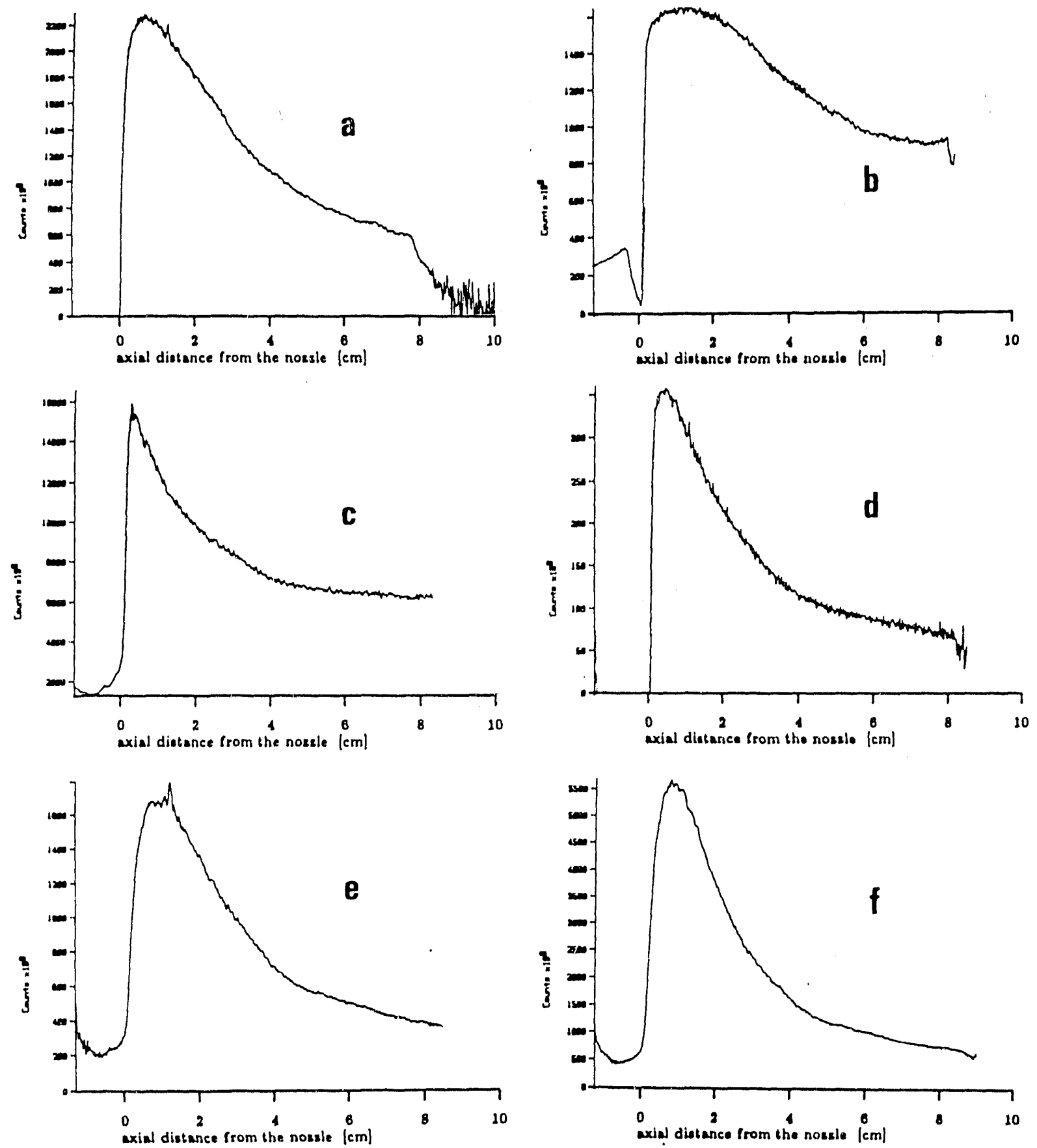

Fig. 25 
$\mathrm{CH}_{4}$
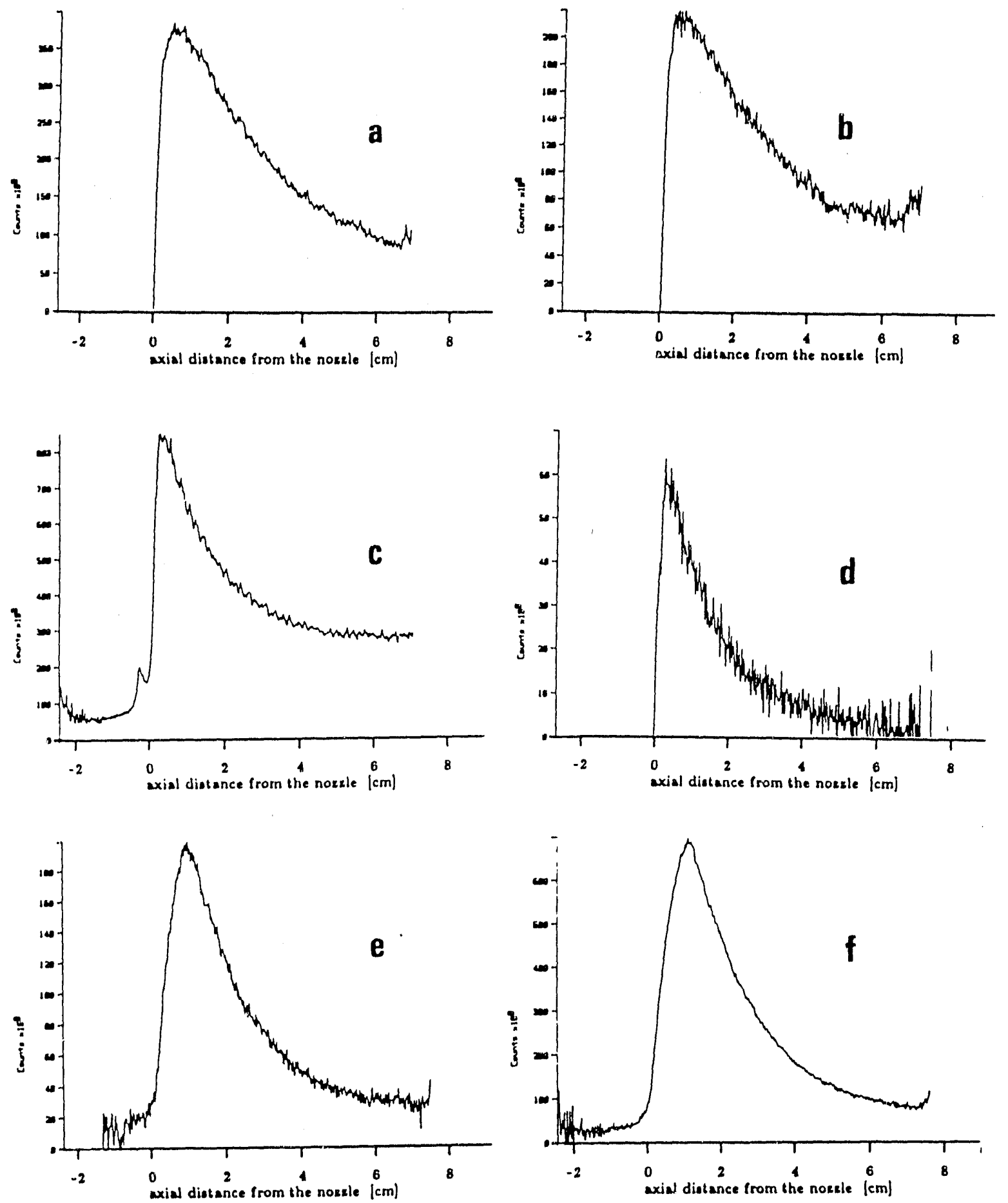

Fig. 26 
$\mathrm{CH}_{4}$
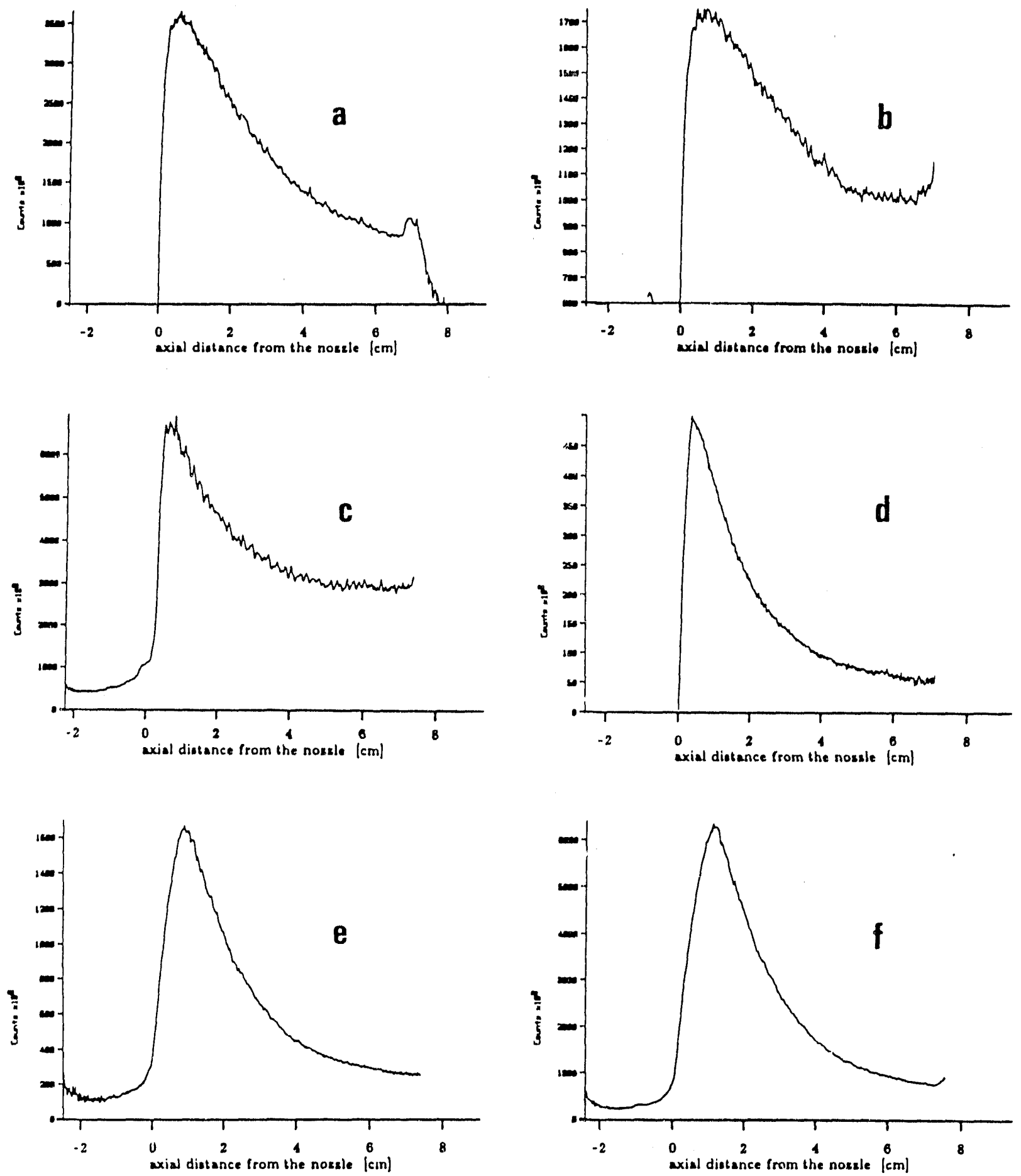

Fig. 27 

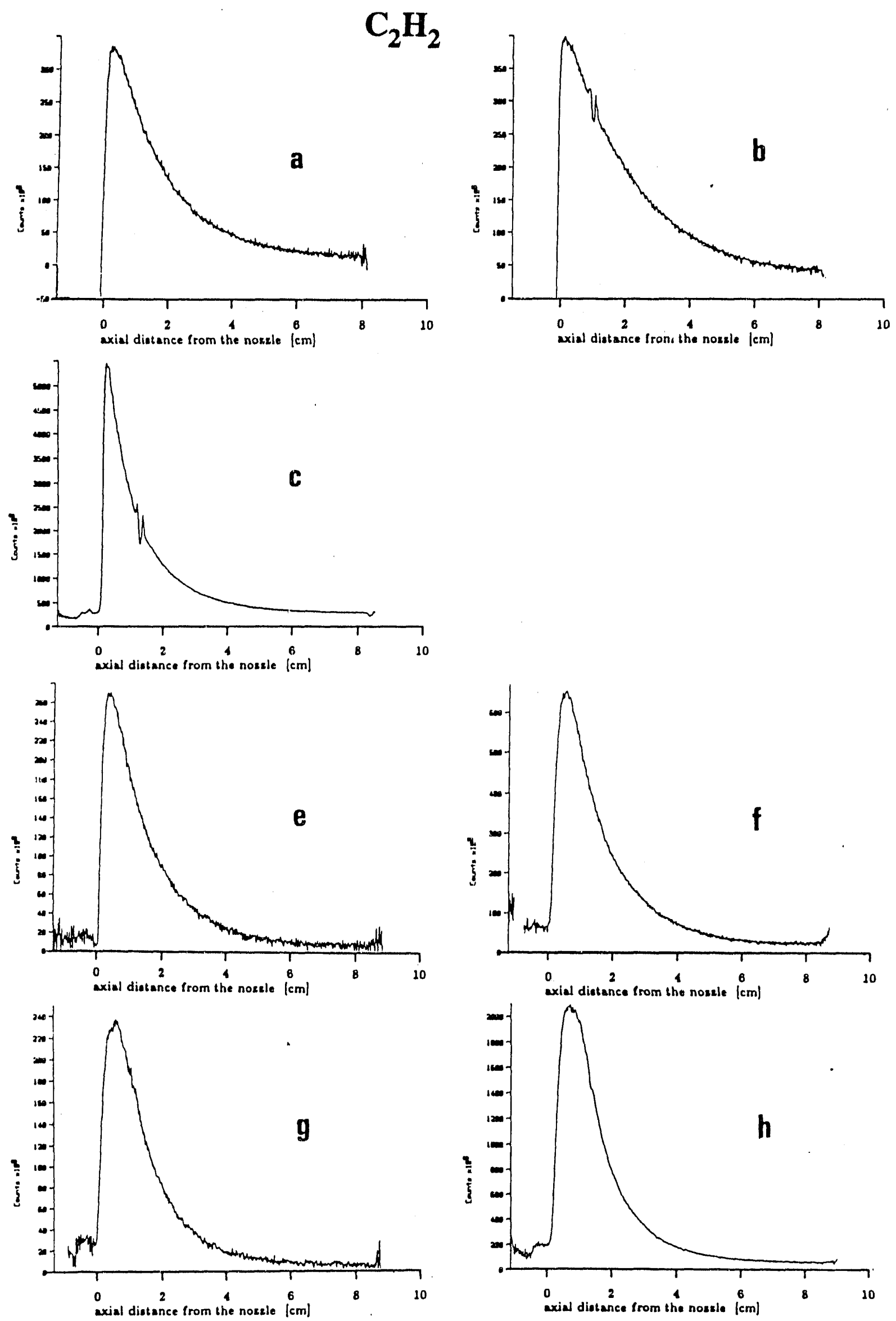

Fig. 28 

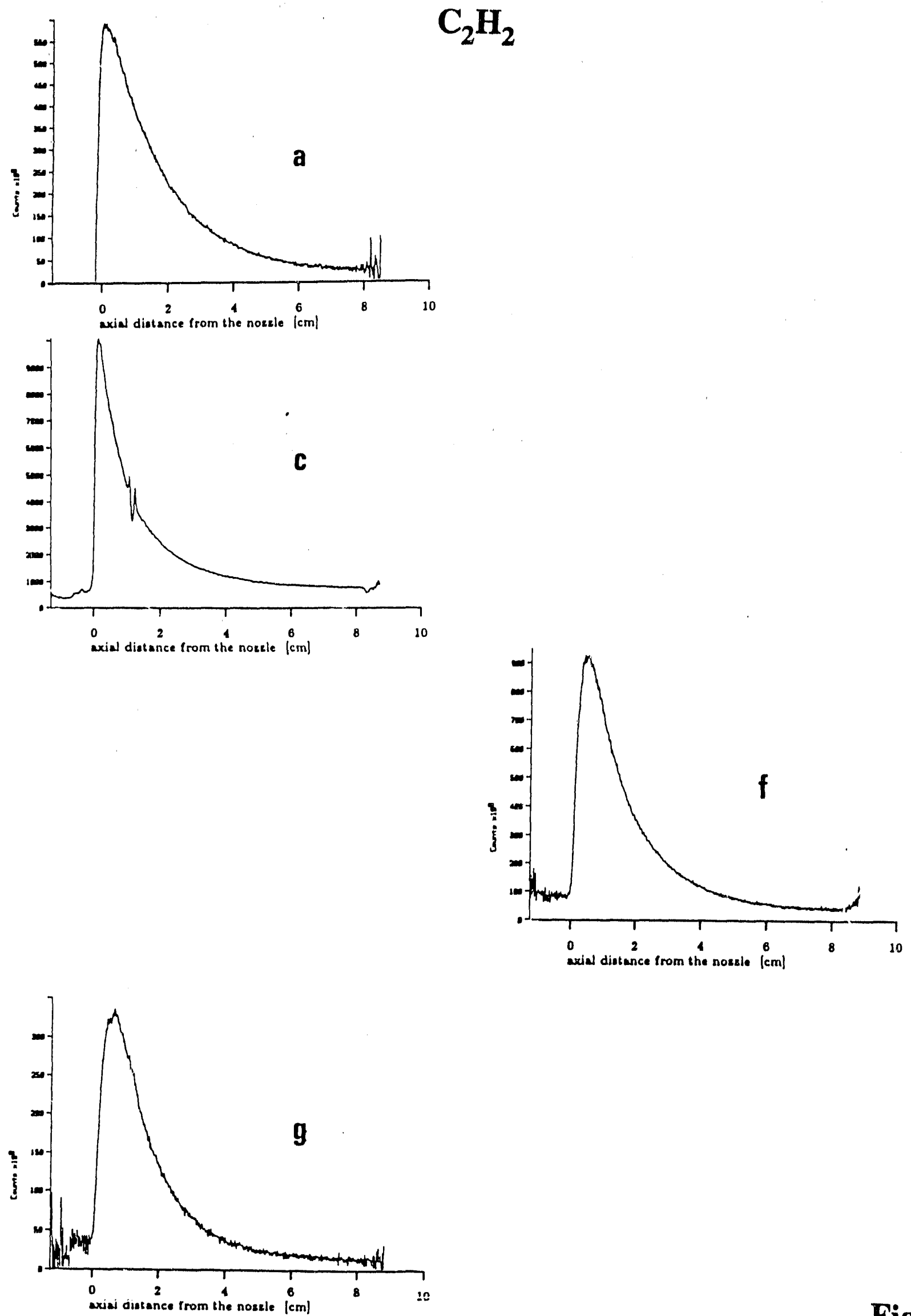

$\mathrm{C}_{2} \mathrm{H}_{2}$ 10 

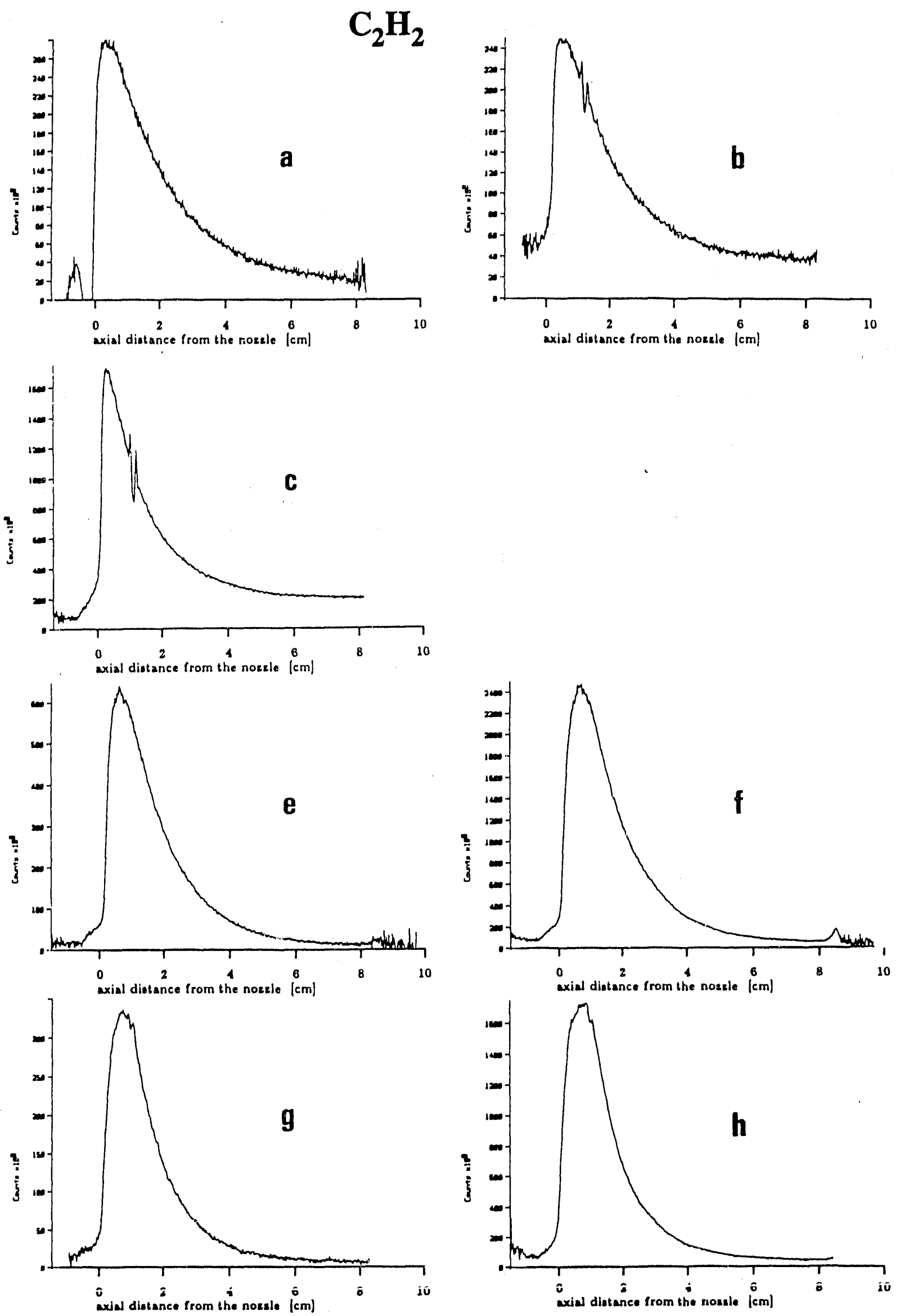

Fig. 30 

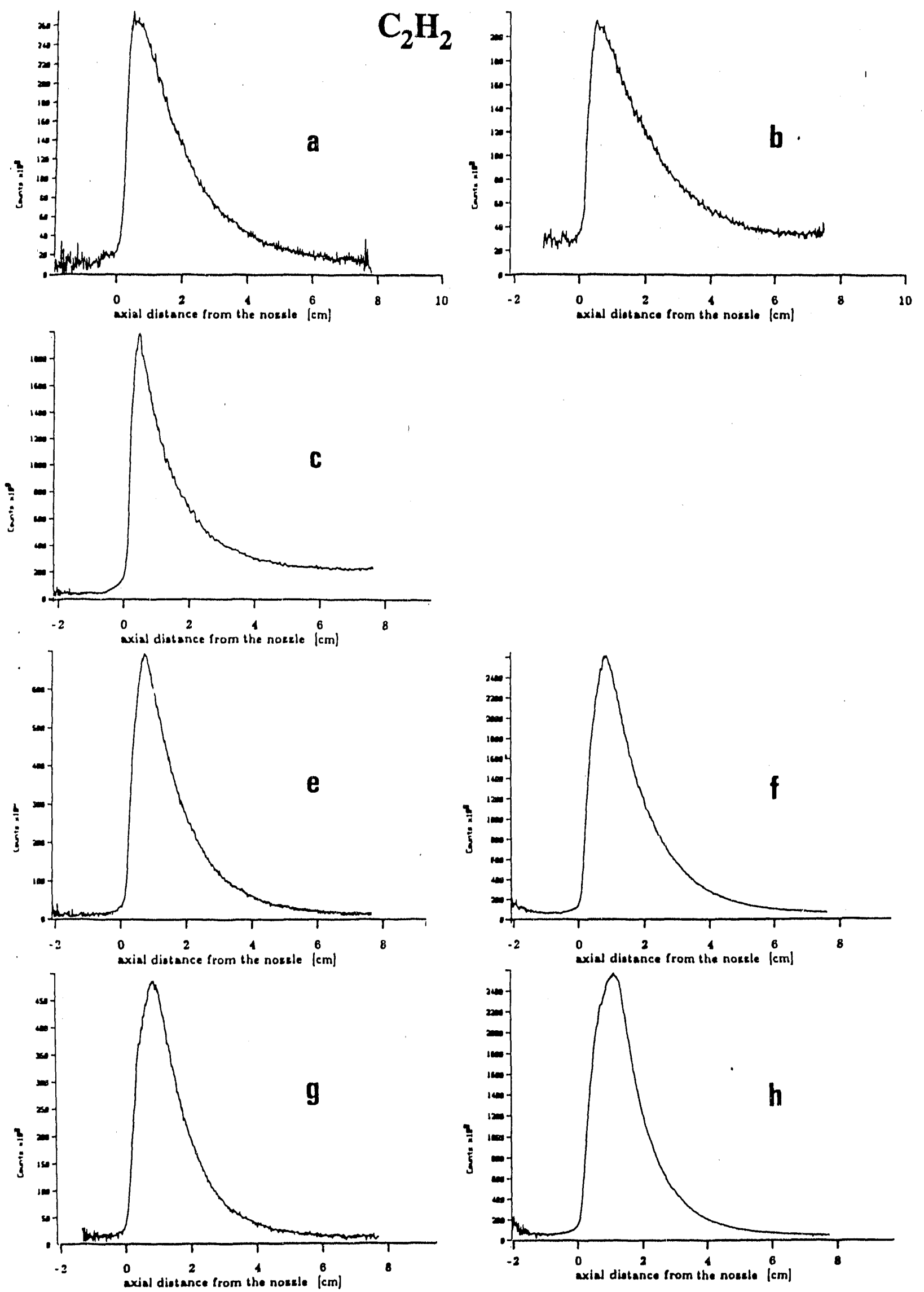

Fig. 31 

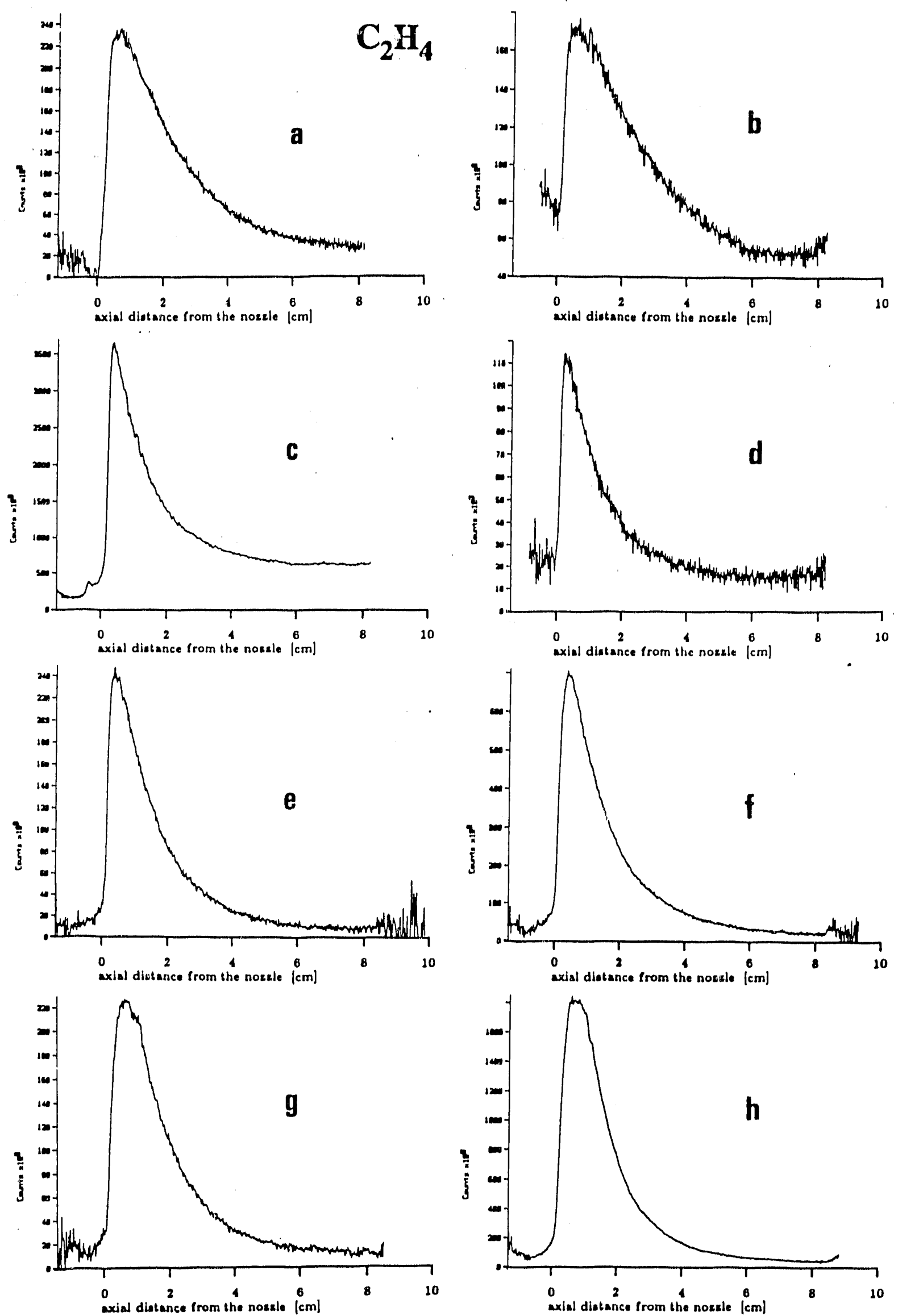

Fig. 32 

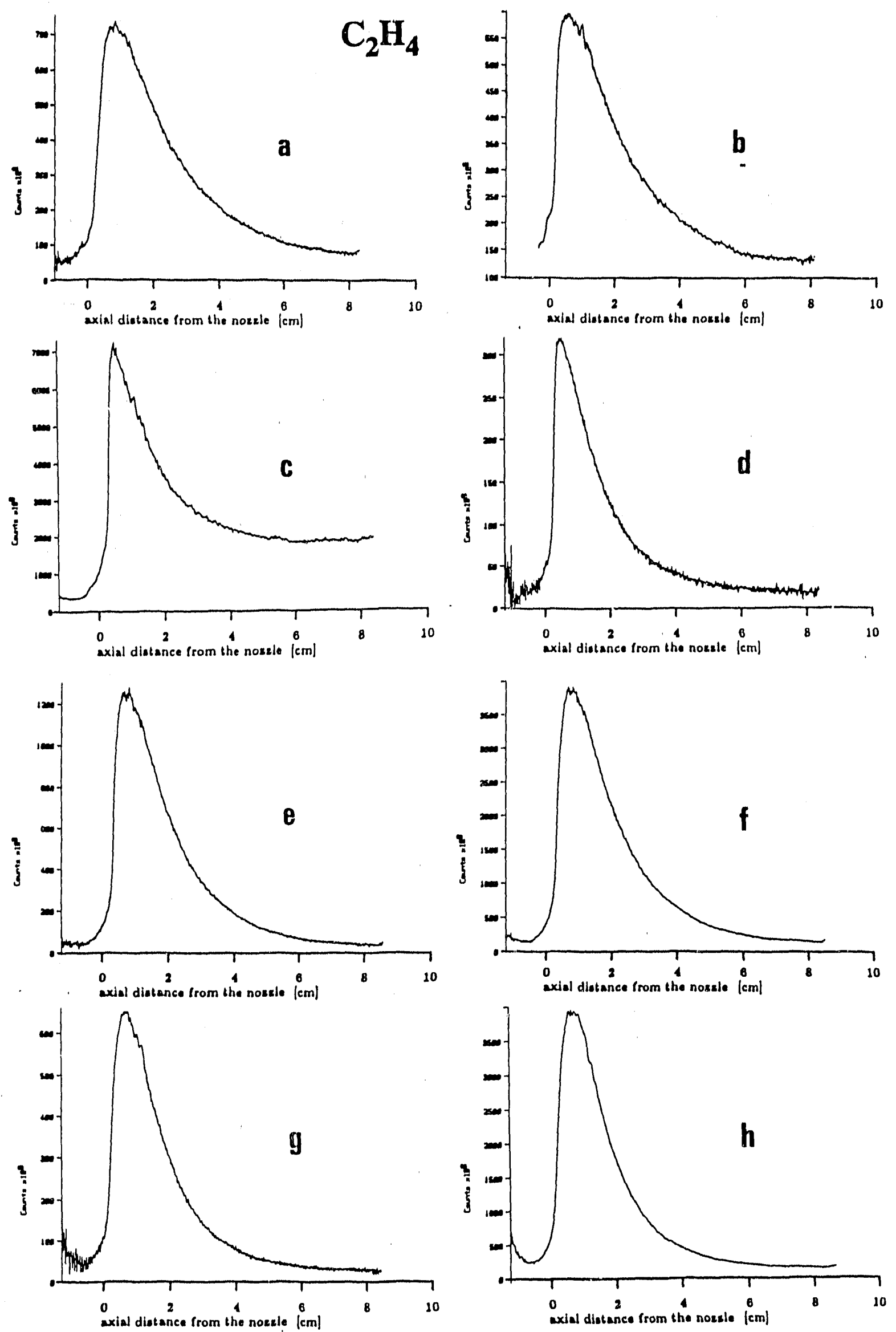

Fig. 33 
CO
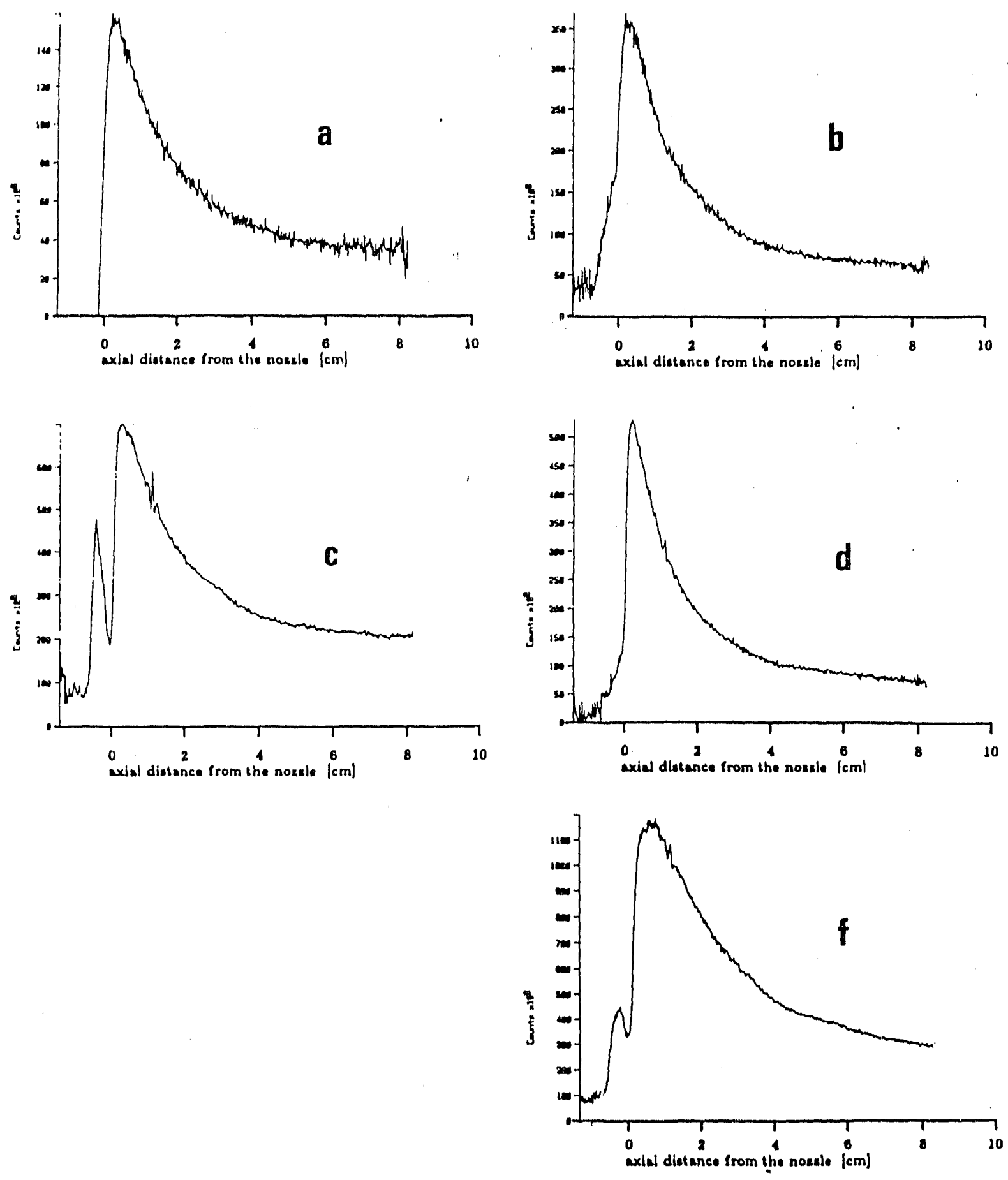

Fig. 34 
CO
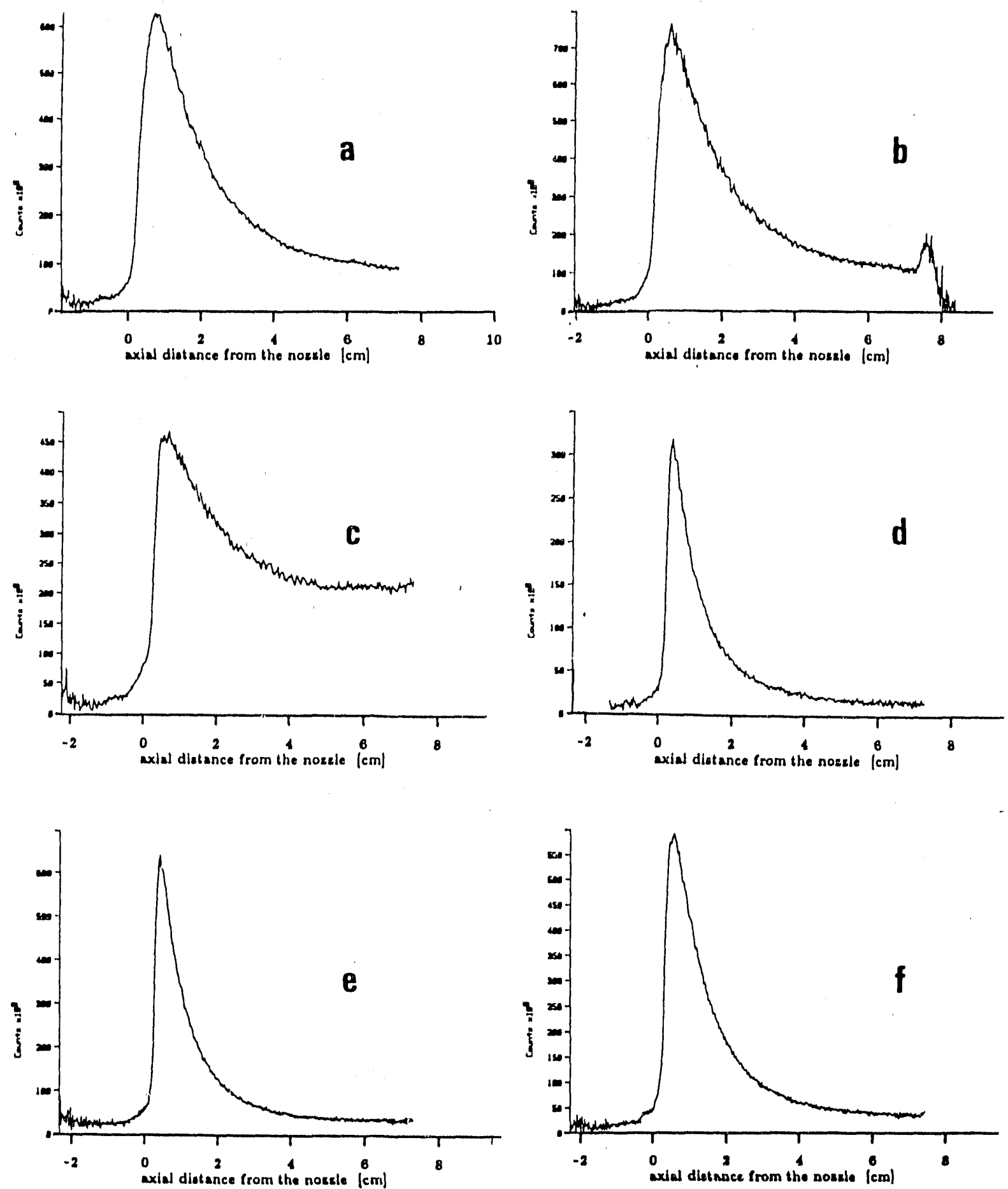

Fig. 35 
-END-

DATE FILMED

$12 / 28 / 90$ 